\title{
Hairless as a novel component of the Notch signaling pathway
}

Steven W Miller ${ }^{1}$, Artem Movsesyan ${ }^{1}$, Sui Zhang ${ }^{1}$, Rosa Fernández ${ }^{2,3}$, James W Posakony ${ }^{1}$

${ }^{1}$ Division of Biological Sciences, Section of Cell and Developmental Biology, University of California San Diego, La Jolla, United States

${ }^{2}$ Bioinformatics and Genomics Unit, Center for Genomic Regulation, Barcelona, Spain

${ }^{3}$ Current address: Department of Life Sciences, Barcelona Supercomputing Center, Barcelona, Spain

For correspondence: jposakony@ucsd.edu 


\begin{abstract}
Suppressor of Hairless $[\mathrm{Su}(\mathrm{H})]$, the transcription factor at the end of the Notch pathway in Drosophila, utilizes the Hairless protein to recruit two co-repressors, Groucho (Gro) and C-terminal Binding Protein (CtBP), indirectly. Hairless is present only in the Pancrustacea, raising the question of how $\mathrm{Su}(\mathrm{H})$ in other protostomes gains repressive function. We show that $\mathrm{Su}(\mathrm{H})$ from a wide array of arthropods, molluscs, and annelids includes motifs that directly bind Gro and CtBP; thus, direct co-repressor recruitment is ancestral in the protostomes. How did Hairless come to replace this ancestral paradigm? Our discovery of a protein (S-CAP) in Myriapods and Chelicerates that contains a motif similar to the $\mathrm{Su}(\mathrm{H})$-binding domain in Hairless has revealed a likely evolutionary connection between Hairless and Metastasis-associated (MTA) protein, a component of the NuRD complex. Sequence comparison and widely conserved microsynteny suggest that S-CAP and Hairless arose from a tandem duplication of an ancestral MTA gene.
\end{abstract}




\section{Introduction}

A very common paradigm in the regulation of animal development is that DNAbinding transcriptional repressors bear defined amino acid sequence motifs that permit them to recruit, by direct interaction, one or more common co-repressor proteins that are responsible for conferring repressive activity. Two such universal co-repressors are Groucho (Gro) and C-terminal Binding Protein (CtBP).

The ancient and highly conserved transcription factor Suppressor of Hairless $[\mathrm{Su}(\mathrm{H})]$ functions at the terminus of the widely utilized Notch cell-cell signaling pathway. $\mathrm{Su}(\mathrm{H})$ is converted into an activator by signaling through the Notch receptor, but in the absence of signaling it functions as a repressor. Earlier studies have revealed that in many settings in Drosophila, $\mathrm{Su}(\mathrm{H})^{\prime}$ s repressive activity depends on binding to the Hairless protein (Figure 1). Hairless includes separate Gro- and CtBP-binding motifs, which permit it to function as an adaptor to bring these two corepressors to $\mathrm{Su}(\mathrm{H})$ (Figure 1B) (Barolo et al. 2002). Thus, the $\mathrm{Su}(\mathrm{H}) / \mathrm{H}$ partnership in the fly represents a notable exception to the rule of direct co-repressor recruitment.

As genome and transcriptome sequences have become available for more and more insects and other arthropods, we have searched for possible Hairless orthologs in a wide variety of species, in an attempt to determine the protein's phylogenetic distribution. We have found that Hairless is confined to the Pancrustacea (or Tetraconata), a clade of arthropods that includes the Crustacea and Hexapoda (Misof et al. 2014; Kjer et al. 2016). While this indicates that Hairless was gained at least 500 Mya, it also raises the question of how $\mathrm{Su}(\mathrm{H})$ in other protostomes gains repressive activity.

Here we present evidence that direct co-repressor recruitment by $\mathrm{Su}(\mathrm{H})$ is likely to be ancestral in the protostomes. We show that $\mathrm{Su}(\mathrm{H})$ in a broad range of protostomes, 
including arthropods, molluscs, and annelids, bears both a short linear motif that mediates binding of CtBP and a novel motif for direct recruitment of Gro. Thus, the evolutionary appearance of Hairless has permitted the replacement of an ancient and predominant regulatory mechanism (direct co-repressor recruitment) with a novel one (indirect recruitment).

What can we learn about the evolutionary history of Hairless? While Hairless itself is found only in the Pancrustacea, we show that the genomes of Myriapods and Chelicerates encode a protein with clear sequence and functional similarities to Hairless. These proteins include a motif that strongly resembles the $\mathrm{Su}(\mathrm{H})$-binding domain of Hairless, and we demonstrate that this motif from the house spider Parasteatoda tepidariorum does indeed bind $\mathrm{Su}(\mathrm{H})$. In addition, these Myriapod and Chelicerate proteins also include one or more canonical motifs for recruitment of CtBP. Accordingly, we designate these factors as "Su(H)-Co-repressor Adaptor Proteins" (SCAPs).

Finally, further sequence analyses, along with the discovery of conserved microsynteny, have provided substantial evidence that Hairless and the S-CAPs are likely to be homologous and that they arose from a duplication of the gene encoding Metastasis-associated (MTA) protein, a component of the nucleosome remodeling and deacetylase (NuRD) complex.

An intriguing question in evolutionary biology concerns the path by which a particular clade has escaped a strongly selected character that has been conserved for hundreds of millions of years. We believe that our study has yielded valuable insight into both the emergence of an evolutionary novelty and its replacement of an ancestral paradigm. 


\section{Results}

\section{Hairless is present only in the Pancrustacea}

We have conducted extensive BLAST searches of genome and transcriptome sequence data for a wide variety of metazoa in an attempt to define the phylogenetic distribution of Hairless. We find that Hairless as originally described (Bang and Posakony 1992; Maier et al. 1992; Maier et al. 2008) is confined to the Pancrustacea (or Tetraconata), and occurs widely within this clade, including the Hexapoda, Vericrustacea, and Oligostraca (Figure 2A). By contrast, no evidence for a true Hairless gene has been detected in either Myriapods or Chelicerates, even in cases where substantially complete genome sequence assemblies are available.

The enormous variation in the size of the Hairless protein in various Pancrustacean clades is worthy of note (Figure 1A). The known extremes are represented by the Diplostracan (shrimp) Eulimnadia texana (343 aa) (Baldwin-Brown et al. 2018) and the Dipteran (fly) Protophormia terraenovae (1614 aa) (Hase et al. 2017), a 4.7-fold difference. There is a broad tendency for the size of the protein to be relatively stable within an order (Supplementary file 1). Thus, as noted previously (Maier et al. 2008), the Hymenoptera generally have a small Hairless (of the order of 400 aa; see Figure 1A), while the Diptera typically have a much larger version (of the order of 1000 aa or more). Notable exceptions to this pattern of uniformity are aphids, where Hairless is typically $\sim 900$ aa compared to $\sim 400$ aa in other Hemiptera, and chalcid wasps, where the protein is over 500 aa instead of the Hymenoptera-typical 400 aa noted above (Supplementary file 1). Smaller Hairless proteins retain all five conserved motifs / domains characteristic of this factor (Maier et al. 2008), while the regions that flank and lie between these sequences are reduced in size (Figure 1A; Supplementary file 2). 


\section{A known CtBP-binding motif is present in the non-conserved $\mathrm{N}$-terminal region of $\mathrm{Su}(\mathrm{H})$ in a wide variety of protostomes}

The apparent confinement of the Hairless co-repressor adaptor protein to the

Pancrustacea raises the question of the mechanism(s) by which $\mathrm{Su}(\mathrm{H})$ in other

protostomes might recruit co-repressor proteins to mediate its repressor function. Of

course, other protostomes need not utilize the Gro and CtBP co-repressors for this

purpose; different co-repressors might substitute. Nevertheless, we first sought to

identify known binding motifs for Gro and $\mathrm{CtBP}$ in $\mathrm{Su}(\mathrm{H})$ from arthropods lacking

Hairless. As shown in Table 1, we found a canonical CtBP recruitment motif of the

form $\mathrm{P} \phi \mathrm{D} \phi \mathrm{S}$ (where $\phi=\mathrm{I}, \mathrm{L}, \mathrm{M}$, or $\mathrm{V}$ ) in predicted $\mathrm{Su}(\mathrm{H})$ proteins from a variety of

Myriapods and Chelicerates, including the centipede Strigamia maritima, the tick Ixodes

scapularis, the spider Parasteatoda tepidariorum, the horseshoe crab Limulus polyphemus,

and the scorpion Centruroides sculpturatus. These motifs are all located in the non-

conserved N-terminal region of $\mathrm{Su}(\mathrm{H})$ (Supplementary file 3).

Extending this sequence analysis to other protostome phyla led to the finding that a similar $\mathrm{P} \phi \mathrm{D} \phi \mathrm{S}$ motif occurs in the $\mathrm{N}$-terminal region of $\mathrm{Su}(\mathrm{H})$ from a large number of molluscs and annelids, as well as from multiple Nemertea, Brachiopoda, Phoronida, and monogonont rotifers, and also from some flatworms (Table 1). It is notable, by contrast, that we do not find $\mathrm{CtBP}$-binding motifs present in $\mathrm{Su}(\mathrm{H})$ from nematodes.

Nevertheless, given the broad phylogenetic distribution of the $\mathrm{P} \phi \mathrm{D} \phi S$ motif in $\mathrm{Su}(\mathrm{H})$ from both Ecdysozoa and Lophotrochozoa, our observations strongly suggest that direct recruitment of $\mathrm{CtBP}$ by $\mathrm{Su}(\mathrm{H})$ is ancestral in the protostomes.

To verify that the shared $\mathrm{P} \phi \mathrm{D} \phi S$ motif in protostome $\mathrm{Su}(\mathrm{H})$ proteins can indeed mediate direct recruitment of $\mathrm{CtBP}$, we carried out an in vitro pulldown assay using 
GST-tagged Drosophila CtBP (bound to Glutathione Sepharose beads) and a His-tagged fragment of Strigamia maritima $\mathrm{Su}(\mathrm{H})$ (Figure 3A). We found that the two proteins do interact directly and robustly, in a manner that is dependent on the integrity of the PVDLS motif in Strigamia Su(H).

\section{A novel conserved motif in protostome $\mathrm{Su}(\mathrm{H})$ binds the Gro co-repressor}

In addition to a $\mathrm{P} \phi \mathrm{D} \phi S \mathrm{CtBP}$-binding motif, we have found that $\mathrm{Su}(\mathrm{H})$ from a wide variety of protostomes includes a novel motif similar to GSLTPPDKV (Table 1). Where present, this sequence typically lies a short (but variable) distance C-terminal to the $\mathrm{P} \phi \mathrm{D} \phi S$ motif, also within the non-conserved N-terminal region of the protein (Supplementary file 3). The GSLTPPDKV motif is particularly prevalent in $\mathrm{Su}(\mathrm{H})$ from the Trochozoa, which includes annelids, sipunculans, molluscs, nemerteans, brachiopods, and phoronids (Kocot et al. 2017). Among the Ecdysozoa, it appears consistently in $\mathrm{Su}(\mathrm{H})$ from Crustacea and Myriapoda, and in small subsets of both Hexapoda (Ephemeroptera, Odonata, Zygentoma, Archaeognatha, Diplura, and Collembola) and Chelicerata [harvestmen (Opiliones) and Scorpiones]. The motif is absent from $\mathrm{Su}(\mathrm{H})$ in all other insect orders, and we have not found it so far in $\mathrm{Su}(\mathrm{H})$ from nematodes, flatworms, rotifers, or tardigrades; it is, however, found in the onychophoran Euperipatoides kanangrensis (Table 1). Perhaps surprisingly, the motif is present in $\mathrm{Su}(\mathrm{H})$ from the acorn worms Saccoglossus kowalevskii and Ptychodera flava (Simakov et al. 2015), which are hemichordates (deuterostomes).

Using an in vitro pulldown assay, we tested the possibility that the GSLTPPDKV motif mediates binding of the Gro co-repressor (Figure 3B). Indeed, we find that GSTtagged Gro protein interacts strongly with a His-tagged protein bearing this motif at its C-terminus, and that this binding is abolished when the motif is replaced by alanine 
residues. We conclude that $\mathrm{Su}(\mathrm{H})$ from a broad range of protostomes is capable of directly recruiting both CtBP and Gro (Table 1), and that this capacity is hence very likely to be ancestral in this clade.

\section{Retention of the hybrid state: Species that have both Hairless and the co-repressor- binding motifs in $\mathrm{Su}(\mathrm{H})$}

The evolutionary emergence of Hairless as an adaptor protein capable of mediating the indirect recruitment of both Gro and $\mathrm{CtBP}$ to $\mathrm{Su}(\mathrm{H})$ might be expected to relieve a selective pressure to retain the ancestral Gro- and CtBP-binding motifs in $\mathrm{Su}(\mathrm{H})$ itself. And indeed, we find that $\mathrm{Su}(\mathrm{H})$ from multiple insect orders comprising the Neoptera lacks both of these sequences (Figure 2B). Strikingly, however, we have observed that Crustacea and a small group of Hexapoda retain both traits (Figure 2B). Thus, multiple representatives of the Branchiopoda, Malacostraca, and Copepoda, along with Ephemeroptera, Odonata, Zygentoma, Archaeognatha, Diplura, and Collembola, have both a canonical Hairless protein (including its Gro- and CtBP-binding motifs) and Groand CtBP-binding motifs within $\mathrm{Su}(\mathrm{H})$. These clades, then, appear to have retained a "hybrid intermediate" state (Baker et al. 2012) characterized by the presence of both corepressor recruitment mechanisms.

\section{Myriapods and Chelicerates encode a protein with similarity to Hairless}

While canonical Hairless proteins are confined to the Pancrustacea, we have discovered that the genomes of Myriapods and Chelicerates nevertheless encode a protein with intriguing similarities to Hairless. Most notable is the presence of a motif that strongly resembles the "Su(H) binding domain" (SBD) of Hairless, which mediates its highaffinity direct interaction with $\mathrm{Su}(\mathrm{H})$ (Figure 1; Figure 4A). We will refer to these proteins as "S-CAPs"; the basis for this designation will be made clear in forthcoming 
figures. We note that the occurrence of this protein in the centipede Strigamia maritima has also recently been reported by Maier (Maier 2019). In the Pancrustacea, the Nterminal and C-terminal halves of the Hairless SBD are encoded by separate exons (Figure 4B). Strikingly, the related motif in Myriapod and Chelicerate S-CAPs is likewise encoded by separate exons, with exactly the same splice junction as in Hairless (Figure 4B). We believe that this is highly unlikely to be coincidental, and is instead strongly suggestive of an evolutionary relationship between Hairless and S-CAPs.

A recent structural analysis of the $\mathrm{Su}(\mathrm{H})$-Hairless protein complex identified several residues in the Hairless SBD that are involved in binding to the C-terminal domain (CTD) of $\mathrm{Su}(\mathrm{H})$ (Yuan et al. 2016) (Figure 4A). These include four hydrophobic amino acids in the main body of the SBD (L235, F237, L245, and L247; these are highlighted in red in Figure 4A). Note that the Myriapod and Chelicerate S-CAP motifs share these same residues. In addition, a tryptophan (W258) C-terminal to the main body of the Hairless SBD also participates in binding to $\mathrm{Su}(\mathrm{H})$ (Figure 4A). Myriapod and Chelicerate S-CAPs all include a tryptophan residue at a similar position C-terminal to the main SBD-like domain (Figure 4A). Moreover, this particular W residue in both Hairless and the S-CAPs is followed by a hydrophobic residue, typically V or I. These sequence features, we suggest, is further strong evidence of a common ancestry for the respective segments of Hairless and S-CAPs.

A third structural similarity between Hairless and S-CAPs is the presence in the latter of one or more short linear motifs capable of binding the CtBP co-repressor (Figure 5A). These motifs typically reside in the C-terminal half of the S-CAPs, superficially resembling the C-terminal location of Hairless's CtBP recruitment motif. 
A table listing representative examples of Myriapod and Chelicerate S-CAPs is provided as Supplementary file 4, and an annotated FASTA file of their amino acid sequences is included as Supplementary file 5.

\section{Spider S-CAP binds to Drosophila Su(H)}

Given the clear sequence similarity between the Hairless SBD and the SBD-like motif in Myriapod and Chelicerate S-CAPs, we investigated whether the latter motif is likewise capable of mediating direct binding to $\mathrm{Su}(\mathrm{H})$. As noted above, the Hairless SBD interacts specifically with the CTD of $\mathrm{Su}(\mathrm{H})$. Since this domain in $\mathrm{Su}(\mathrm{H})$ is very highly conserved throughout the Bilateria and Cnidaria, we thought it reasonable to utilize Drosophila $\mathrm{Su}(\mathrm{H})$ for this binding assay. As shown in Figure 4C, we find that a 200amino-acid segment of S-CAP from the spider Parasteatoda tepidariorum binds directly to Drosophila $\mathrm{Su}(\mathrm{H})$ in vitro. This interaction depends strictly on the integrity of the five residues that in Hairless have been shown to contact the $\mathrm{Su}(\mathrm{H}) \mathrm{CTD}$ (highlighted in red in Figure 4A).

Given the presence of one or more CtBP recruitment motifs in the Myriapod and Chelicerate S-CAP proteins (Figure 5A), along with the ability of their SBD-like domains to bind $\mathrm{Su}(\mathrm{H})$ (Figure $4 \mathrm{C})$, we have designated these as "Su(H)-Co-repressor Adaptor Proteins" (S-CAPs).

\section{Chelicerate S-CAP proteins are related to Metastasis-Associated (MTA) proteins}

In addition to their similarities to Hairless, the S-CAP proteins of Chelicerates include two regions with strong sequence homology to the Metastasis-associated (MTA) protein family, which is highly conserved among Metazoa. The MTA proteins play an important role in transcriptional regulation via their function as core components of the nucleosome remodeling and deacetylase (NuRD) complex (Allen et al. 2013). The N- 
terminal half of MTAs includes four well-defined functional domains: BAH (BromoAdjacent Homology), ELM2 (Egl-27 and MTA1 homology), SANT (Swi3, Ada2, N-CoR, and TFIIIB), and GATA-like zinc finger (Millard et al. 2014) (Figure 5B). Of these, the ELM2 and SANT domains are retained at the N-terminal end of Chelicerate S-CAPs (Figure 5B; Figure S1A). This is highly likely to have functional significance, as the ELM2 and SANT domains of MTA proteins work together to recruit and activate the histone deacetylases HDAC1 and HDAC2 (Millard et al. 2013). Further suggesting homology between Chelicerate S-CAPs and MTAs is the observation that their shared ELM2 and SANT domains are each encoded by two exons with exactly the same splice junction (Figure 5C).

It is noteworthy that, despite sharing the SBD-like and CtBP recruitment motifs of Chelicerate S-CAPs, the available Myriapod S-CAP protein sequences lack the Nterminal ELM2 and SANT homologies with MTA proteins (Figure 5B). Consistent with this, the SBD motif in Myriapod S-CAPs lies much closer to the protein's N terminus than the SBD motif in Chelicerate S-CAPs, suggesting that simple loss of the ELM2/SANT-encoding exons might underlie this difference between the two S-CAP clades. Likewise, Hairless proteins are devoid of clear similarities to MTAs.

In addition to their SBD and ELM2/SANT domains, Chelicerate S-CAPs share a third region of homology that lies between the ELM2 and SANT sequences (Figure 5figure supplement 1A). This region is absent from both Hairless and the Myriapod SCAPs. Conversely, Myriapod S-CAPs include three segments of sequence similarity in their C-terminal regions that are not found in either Hairless or Chelicerate S-CAPs (Figure 5-figure supplement 1B).

\section{Conserved microsynteny between $M T A$ and S-CAP/Hairless genes}


Our analysis of the genomic locations of genes encoding MTA proteins in Arthropoda, Hairless in Pancrustacea, and S-CAPs in Myriapods and Chelicerates has yielded the surprising finding that proximate or near-proximate linkage between MTA and Hairless genes or between MTA and S-CAP genes is broadly conserved among arthropods (Figure 6; Supplementary file 1; Supplementary file 4). Thus, in the centipede Strigamia maritima, the gene encoding S-CAP lies immediately upstream of that encoding MTA, in the same orientation (Figure 6; Supplementary file 4). A similar linkage relationship between $S-C A P$ and $M T A$ genes is seen in many arachnids, including the spiders Nephila clavipes (Supplementary file 4) and Parasteatoda tepidariorum (Figure 6; Supplementary file 4) and the mites Achipteria coleoptrata and Sarcoptes scabiei (Supplementary file 4). Likely due at least in part to its history of whole-genome duplication (Nossa et al. 2014; Kenny et al. 2016), the horseshoe crab Limulus polyphemus (representing the Merostomata/Xiphosura) has three paralogous copies of this same $S$ CAP-MTA linkage pairing (Supplementary file 4). Some exceptions to this pattern do exist. In the genomes of the mites Metaseiulus occidentalis (Supplementary file 4) and Varroa destructor (Techer et al. 2019), for example, the genes encoding S-CAP and MTA are far separated from each other.

Close, typically adjacent, linkage between Hairless and MTA genes is likewise widely observed in the genomes of Pancrustacea. Among the Hexapoda, this pattern can be found in many different orders (Supplementary file 1), including Diptera, Lepidoptera, Coleoptera (Figure 6), Hymenoptera (Figure 6), Psocodea, Hemiptera (Figure 6), Thysanoptera, Blattodea, Orthoptera, Odonata, and Collembola. Among the Vericrustacea, adjacent linkage of Hairless and MTA is seen in the shrimp Triops cancriformis (Notostraca) (Supplementary file 1). Nevertheless, exceptions are readily found, even within the same orders as above (Supplementary file 1). Examples include 
Drosophila melanogaster, Ceratitis capitata, and Lucilia cuprina (Diptera; Supplementary file 1), Bicyclus anynana (Lepidoptera), Anoplophora glabripennis, Dendroctonus ponderosae, and Nicrophorus vespilloides (Coleoptera), and Cimex lectularius (Hemiptera; Supplementary file 1).

Interestingly, in some instances Hairless / MTA microsynteny is preserved, but the genes' relative orientation is different (Figure 6; Supplementary file 1). Thus, in the aphids - in contrast to other Hemiptera - MTA lies downstream of Hairless, but in the opposite orientation (Figure 6). In the beetle Harmonia axyridis (Coleoptera), MTA lies upstream of Hairless (Figure 6).

Despite the multiple instances in which it has been lost, we believe that the most parsimonious interpretation of our analysis is that close linkage between MTA and SCAP/Hairless genes is ancestral in the respective taxa (Myriapods/Chelicerates and Pancrustacea). We leave for the Discussion our proposed interpretation of the evolutionary significance of this adjacency. 


\section{Discussion}

\section{The evolution of Hairless represents a shift from the ancestral and dominant paradigm of direct co-repressor recruitment by $\mathrm{Su}(\mathrm{H})$}

Our analysis of sequences from a broad range of protostomes strongly suggests that direct recruitment of the $\mathrm{CtBP}$ and Gro co-repressors by $\mathrm{Su}(\mathrm{H})$ is ancestral in this clade. This is consonant with the fact that direct co-repressor recruitment by DNA-binding repressor proteins in general is a dominant paradigm among Metazoa. This evokes the intriguing question of what might have led to the loss of direct recruitment by $\mathrm{Su}(\mathrm{H})$ in the Neoptera (see Figure 1B) and its replacement by Hairless-mediated indirect recruitment? Does Hairless provide some advantageous functional capacity? Note that this is not intended to suggest that Hairless must be an evolutionary adaptation per se (Lynch 2007); rather, we are asking: What capability might it have conferred that would lead to its retention and the subsequent loss of the recruitment motifs in $\mathrm{Su}(\mathrm{H})$ ?

One appealing possibility is that Hairless may have permitted $\mathrm{Su}(\mathrm{H})$ for the first time to recruit both CtBP and Gro simultaneously to the same target genes. As we have noted, the apparently ancestral P $\phi D \phi S$ and GSLTPPDKV motifs in protostome $\mathrm{Su}(\mathrm{H})$ typically lie quite close to each other in the protein's linear sequence (Supplementary file 3). CtBP ( 400 aa) and Gro ( 700 aa) are both large proteins that engage in oligomerization as part of their functional mechanism (Song et al. 2004; Bhambhani et al. 2011). It is very unlikely that both could bind stably to DNA-bound $\mathrm{Su}(\mathrm{H})$ at the same time. In contrast, the Gro and CtBP recruitment motifs in Hairless are far apart in the linear sequence (Figure 1A) and are separated by a region predicted to be largely disordered (Figure 1-figure supplement 1). We suggest that this might be compatible with simultaneous recruitment of the two co-repressors. 
Whatever may have been the selective forces that led to the loss of direct corepressor recruitment by $\mathrm{Su}(\mathrm{H})$ in the Neoptera and its replacement by Hairlessmediated indirect recruitment, Hairless is a notable evolutionary novelty for having permitted the unusual abandonment of an ancestral and highly conserved paradigm. We suggest that this represents a striking example of "developmental system drift" (True and Haag 2001), in which a common output (widespread "default repression" of Notch pathway target genes) is achieved via distinct molecular mechanisms in different species.

\section{A possible evolutionary pathway for the appearance of Hairless}

We have described here several findings that we believe have important implications for an attempt to reconstruct the history of Hairless as an evolutionary novelty. First, we observe that Hairless is apparently confined to the Pancrustacea, wherein it is widely distributed among diverse taxa (Figure 2A; Supplementary file 1). Second, we have discovered in the sister groups Myriapoda and Chelicerata a protein (S-CAP) with clear sequence homology to the $\mathrm{Su}(\mathrm{H})$ binding domain (SBD) of Hairless (Figure 4A). Significantly, in both Hairless and the S-CAPs these motifs are encoded by contributions from two exons, with the associated splice junction in precisely the same location (Figure 4B; Supplementary file 4). Third, we find that S-CAPs in the Chelicerata include in their N-terminal region strong homology to the ELM2 and SANT domains of MTAs, which themselves are highly conserved among Metazoa, and therefore would have been present in the arthropod common ancestor (Figure 5B,C). Finally, our analysis indicates that close, usually adjacent, linkage of Hairless and MTA genes (in the Pancrustacea) and between S-CAP and MTA genes (in the Myriapoda and 
Chelicerata) is widespread (Figure 6; Supplementary file 1; Supplementary file 4), and hence very likely to be ancestral, in these taxa.

While any attempt to infer the sequence of evolutionary events that led to the appearance of Hairless is necessarily speculative, we believe that the above findings offer substantial support for the following hypothetical pathway. We propose that in a deep arthropod ancestor a tandem duplication of the MTA gene occurred. One copy retained the strong sequence conservation (and presumably ancestral function) of metazoan MTA genes, while the second copy diverged very substantially, eventually encoding a protein that had lost all but the ELM2 and SANT domains of the MTA ancestor. The extensive reconfiguration of this paralog also included the eventual acquisition of the SBD motif and the addition of one or more CtBP recruitment motifs (see Figure 7 for some possible sources of these components). In the Myriapod lineage, even the ELM2 and SANT domains were eventually lost. In the Pancrustacea, we suggest that this same divergent MTA paralog evolved to become Hairless. Beyond the alterations described for the Myriapoda, this would have involved the acquisition of sequences encoding additional now-conserved domains and motifs, including the Gro recruitment motif (Supplementary file 2). This radical evolutionary transformation resulted in a protein with little or no remaining homology to its MTA ancestor, and with an entirely novel regulatory function (Holland et al. 2017).

In this context, it is of interest that the Drosophila Mi-2/Nurd complex - which includes the MTA protein — has recently been shown to engage in direct repression of multiple Notch pathway target genes, independent of both $\mathrm{Su}(\mathrm{H})$ and Hairless (Zacharioudaki et al. 2019). Whether this activity preceded the emergence of Hairless is unknown, but the possibility that it is in some way connected to Hairless's evolutionary history is indeed intriguing. 


\section{Materials and methods}

\section{Sequence searches, analysis, and annotation}

Genome and transcriptome sequences encoding Hairless, Suppressor of Hairless, SCAP, and MTA proteins from a wide variety of species were recovered via BLAST searches, using either the online version at the NCBI website (Boratyn et al. 2013) or the version implemented by the BlastStation-Local64 desktop application (TM Software, Inc.). Sequences were analyzed and annotated using the GenePalette (Rebeiz and Posakony 2004; Smith et al. 2017) and DNA Strider (Marck 1988; Douglas 1995) desktop software tools. Analysis of predicted disordered regions in Hairless was conducted using DISOPRED3 on the PSIPRED server (Buchan et al. 2013; Jones and Cozzetto 2015).

\section{Generation of constructs for GST pulldown experiments Strigamia maritima $\mathrm{Su}(\mathrm{H})$ protein constructs to test $\mathrm{CtBP}$ binding}

A codon-optimized fragment corresponding to exons 2 and 3 from S. maritima $\mathrm{Su}(\mathrm{H})$ mRNA was synthesized by Genewiz, Inc., and cloned into pRSET-C using Acc65I and BamHI restriction sites. The CtBP-motif mutant was subsequently generated by overlap extension PCR (Ho) using the primers HISsmarSUH-f

(CGCTGGATCCGCGGCCAGTATGAC), HISsmarSUH-r (CCATGGTACCAGTTATGCGTGGTG), HISsmarSUHctbpm-f (AACCACgCCGcaGcTGcGgCTAACAGCCATCGCGGTGAAGGCGGCCAC), HISsmarSUHctbpm-r (GCTGTTAGcCgCAgCtgCGGcGTGGTTGTCGGCGAAGTGAGGGGTCAG). After sequence confirmation, this fragment was also cloned into pRSET-C using the same enzymes. Binding of these constructs to Drosophila melanogaster CtBP was assayed using GST alone and a GST-CtBP fusion protein (Nibu et al. 1998). 


\section{Constructs to test potential Gro-binding motif in Strigamia maritima $\mathrm{Su}(\mathrm{H})$}

A truncated version of HLHm $\beta$ (HLHm $\beta$-WRPWtrunc) was amplified from a pRSETHLHm $\beta$-WT construct using the primers HISmbeta-f (cgatggatccgaATGGTTCTGGAAATGGAGATGTCCAAG) and HISmbetatrunc-r (ccatggtaccagTCACATGGGGCCagaggtggagctggctcgctgggcgc); a version of HLHm $\beta$ with the WRPW motif replaced with the amino acids GSLTPPDKV (HLHm $\beta+S m a r-$ motifWT) was amplified from the WT construct with HISmbeta-f and mbetaSmarSuH-r (ccatggtaccagTCACACTTTATCAGGTGGAGTGAGAGAACCCATGGGGCCagaggtgga gctggcc); and a version of HLHm $\beta$ with the WRPW motif replace with a stretch of 9 alanine residues (HLHm $\beta+$ Smar-motifMUT) was amplified using HISmbeta-f and mbetaSmarSuHmut-r (ccatggtaccagTCAggctgccgctgcggctgccgctgctgcCATGGGGCCagaggtggagctggcc). Each construct was then subsequently cloned into pRSET-C using the restriction enzymes BamHI and Acc65I and sequence verified. Binding of these constructs to Drosophila melanogaster Gro was assayed using GST alone and a GST-Gro fusion protein. The latter construct was made by cloning full-length Gro coding sequence into the pGEX expression vector.

\section{S-CAP/Hairless constructs for $\mathrm{Su}(\mathrm{H})$ interaction analysis}

Codon-optimized fragments from Drosophila melanogaster Hairless (residues 192-389), and Parasteatoda tepidariorum cS-CAP (residues 233-432) as well as 5-alanine mutant substitutions (Dmel: GGRLQFFKDGKFILELARSKDGDKSGW ->

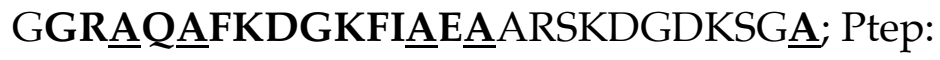

VGSLKFFLGGRLVLKLNAQQDGGSGNKCQW -> 


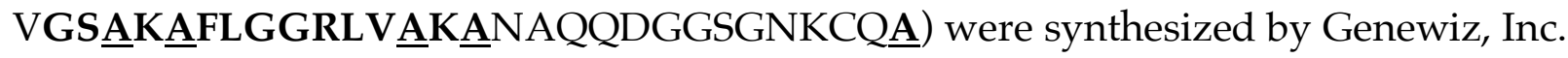
Inserts were subsequently cloned into pRSET-C using the restriction enzymes BamHI and Acc65I. Binding of these constructs to Drosophila melanogaster $\mathrm{Su}(\mathrm{H})$ was assayed using GST alone and a GST-Su(H) fusion protein (Bailey and Posakony 1995).

GST pulldowns using each of these constructs were performed as previously described (Fontana and Posakony 2009).

\section{Synthesized, codon-optimized sequences}

$>$ Smar Su(H)ex2-3 WT (116 aa)

CGCTGGATCCGCGGCCAGTATGACTACCCGCCGCCGTTAGCCAGCACATACAGCCGCGAGGCCG ACCTGTGGAACGTGAACCTGGCCACCTACAGCAGCGCACCGACCACATGCACCGGTGCAACCCC GGCACCTAGCGTTACCGGTTTCTACGCCCAGGCCACCGGCAGCAACAGCGTTAGCCCGAGTAGC GTGAGCCTGACCACCCTGACCCCTCACTTCGCCGACAACCACCCGGTGGACCTGAGCAACAGCC ATCGCGGTGAAGGCGGCCACCTGGATCTGGTGCGCTTCCAGAGCGACCGCGTGGATGCCTACAA GCACGCCAACGGCCTGAGCGTGCATATCCCGGACCACCACGCATAACTGGTACCATGG

$>$ Smar Su(H)ex2-3 mut CGCTGGATCCGCGGCCAGTATGACTACCCGCCGCCGTTAGCCAGCACATACAGCCGCGAGGCCG ACCTGTGGAACGTGAACCTGGCCACCTACAGCAGCGCACCGACCACATGCACCGGTGCAACCCC GGCACCTAGCGTTACCGGTTTCTACGCCCAGGCCACCGGCAGCAACAGCGTTAGCCCGAGTAGC GTGAGCCTGACCACCCTGACCCCTCACTTCGCCGACAACCACgCCGCaGcTGcGgCTAACAGCC ATCGCGGTGAAGGCGGCCACCTGGATCTGGTGCGCTTCCAGAGCGACCGCGTGGATGCCTACAA GCACGCCAACGGCCTGAGCGTGCATATCCCGGACCACCACGCATAACTGGTACCATGG

$>$ Dmel Hairless192-389 WT

CGATGGATCCGAGCAGTGGTTGCAGCAGCAGCTGGCACTGCCAAAATTGGTAAAGGCAGCAACA GCGGTGGCAGTTTTGATATGGGCCGCACACCGATCAGCACCCACGGCAACAATAGTTGGGGTGG CTATGGCGGCCGTTTACAGTTCTTTAAAGATGGCAAGTTTATTTTAGAACTGGCCCGCAGCAAA GATGGCGATAAAAGCGGCTGGGTGAGTGTGACCCGCAAAACCTTTCGCCCGCCGAGTGCAGCAA CCAGCGCAACCGTGACCCCTACCAGTGCCGTGACCACCGCCTACCCGAAGAATGAAAACAGCAC СTCTTTAAGCTTCAGCGACGACAATAGCAGCATTCAGAGCAGCCCGTGGCAGCGTGATCAGCCG TGGAAACAGAGTCGTCCGCGCCGTGGCATCAGCAAAGAACTGTCTTTATTTTTCCACCGCCCGC GCAATAGTACACTGGGTCGTGCAGCCTTACGTACCGCAGCCCGCAAACGTCGTCGTCCGCATGA ACCGCTGACCACCAGCGAAGATCAGCAGCCGATCTTTGCCACCGCAATCAAAGCCGAGAACGGT GATGATACTTTAAAAGCCGAAGCAGCCGAATAACTGGTACCATGG

>Dmel Hairless192-389 5Amut CGATGGATCCGAGCCGTTGTGGCAGCAGCAGCTGGCACTGCCAAAATCGGCAAAGGCAGCAATA GCGGTGGTAGCTTTGACATGGGCCGCACCCCGATTAGCACCCATGGCAACAACAGCTGGGGTGG 
TTATGGTGGTCGTGCCCAAGCTTTTAAAGACGGCAAGTTCATCGCCGAAGCCGCACGCAGCAAA GATGGCGACAAAAGCGGTGCCGTGAGCGTGACCCGCAAAACCTTTCGTCCGCCGAGTGCAGCAA CCAGCGCAACCGTTACCCCGACCAGCGCAGTTACCACCGCCTACCCGAAAAACGAAAACAGCAC СTCTTTAAGCTTTAGCGACGACAACAGCAGCATTCAGAGCAGCCCGTGGCAGCGCGATCAGCCG TGGAAACAGAGCCGTCCTCGTCGCGGCATCAGCAAAGAGCTGTCTTTATTCTTTCATCGCCCGC GCAATAGCACTTTAGGTCGTGCAGCACTGCGCACAGCAGCACGTAAACGTCGTCGCCCGCATGA ACCGCTGACCACCAGCGAAGACCAGCAGCCGATTTTTGCCACCGCAATCAAAGCCGAGAACGGC GATGATACTTTAAAAGCAGAAGCAGCCGAATAACTGGTACCATGG

$>$ Ptep S-CAP233-432 WT

CGATGGATCCGAACCGTGAATACCGAAGATCCGCCGAAGGATAGCATCAACTTTCTGGACCACA GCCGCGTGACCGATCCGTGTAGTGCCGCAAGCGAAACCAGCCTGCCGCAGGATGTGCCGGCAAC AAGCACCGTGGGCAGCCTGAAATTTTTTCTGGGCGGTCGCCTGGTGCTGAAATTAAACGCCCAG CAGGATGGCGGCAGCGGCAATAAATGCCAGTGGGTGCAGAGCAACGATCTGCCGAAACATAGCA ACCATAACAAAAAAGATAAACATAAGAAAAAATTTGCACCGTATAGCTATAGCAGCAGCGGCAC TCAGAAACCGCTGAAGAAAGGCGACGATACCAGTGCCGTGCCGGACTGTGATCCGAGCGGCATC AAAAAGCCGCGCCTGAAAGAGTACGAGACCAGCGAGAATAGCGCCCTGGGTCTGCTGCTGTGCA GCAGCAGTTGGACCCCGCCGGTTGCAGATGGTCAGGAGAGCATTGACGTGGACGATACCAGCAG CAAAACCAGCGAGGGCTATATTAGCCCGATCCTGAGCAACAATAGCCGCACCAGCAAAATCGAC ACCATCAAGCACGATTTTGCCAGCAACCCGAACACCTAACTGGTACCATGG

$>$ Ptep S-CAP233-432 5Amut CGATGGATCCGAACCGTGAACACCGAAGACCCGCCGAAAGATAGCATCAACTTTTTAGACCATA GCCGCGTGACAGACCCGTGCAGTGCCGCAAGTGAAACCTCTTTACCGCAAGATGTGCCGGCAAC CAGCACCGTGGGTAGCGCCAAAGCCTTTCTGGGCGGTCGTCTGGTGGCCAAAGCCAATGCCCAG CAAGATGGTGGTAGTGGTAACAAATGCCAAGCTGTGCAGAGCAACGATCTGCCGAAACACAGCA ATCACAATAAGAAAGACAAACACAAGAAAAAATTTGCCCCGTATAGCTATAGCAGCAGCGGCAC CCAGAAACCGCTGAAAAAAGGCGATGACACCAGCGCAGTGCCGGATTGCGATCCGAGCGGCATT AAGAAACCGCGTTTAAAGGAGTACGAGACCAGCGAAAACAGTGCTTTAGGTTTACTGCTGTGCA GCAGCAGTTGGACACCGCCGGTGGCCGATGGTCAAGAAAGTATCGATGTGGACGACACCAGCAG CAAAACCAGCGAAGGCTACATCAGCCCGATTCTGAGCAACAATAGCCGCACCAGCAAAATTGAT ACCATTAAACATGATTTTGCAAGCAATCCGAATACCTAACTGGTACCATGG 


\section{Acknowledgements}

We thank Scott Rifkin for very useful discussion and input during the preparation of the manuscript. We are grateful to the following artists for making available the illustrations shown in Figure 2A: crab, by Firkin (https: / / openclipart.org/detail/270221/crab-silhouette); monarch butterfly, by carolemagnet (https:/ / openclipart.org/detail/263384/monarch-butterfly); centipede, by Firkin (https: / / openclipart.org/ detail/261126/ centipede-3); spider, by liftarn (https: / / openclipart.org/detail/179190/spider); horseshoe crab, by Gosc (https: / / openclipart.org/detail/174556/horseshoe-crab); tick, by Juhele (https: / / openclipart.org/ detail/279073/ simple-tick-ixodes-ricinus-silhouette). This work was supported by NIH Grants R01GM046993 and R01GM120377 (to JWP). 


\section{References}

Albertin CB, Simakov O, Mitros T, Wang ZY, Pungor JR, Edsinger-Gonzales E, Brenner S, Ragsdale CW, Rokhsar DS. 2015. The octopus genome and the evolution of cephalopod neural and morphological novelties. Nature 524: 220-224.

Allen HF, Wade PA, Kutateladze TG. 2013. The NuRD architecture. Cell Mol Life Sci 70: 3513-3524.

Almada AA, Tarrant AM. 2016. Vibrio elicits targeted transcriptional responses from copepod hosts. FEMS Microbiol Ecol 92: fiw072.

Ando T, Matsuda T, Goto K, Hara K, Ito A, Hirata J, Yatomi J, Kajitani R, Okuno M, Yamaguchi K, Kobayashi M, Takano T et al. 2018. Repeated inversions within a pannier intron drive diversification of intraspecific colour patterns of ladybird beetles. Nat Commun 9: 3843.

Andrade SC, Novo M, Kawauchi GY, Worsaae K, Pleijel F, Giribet G, Rouse GW. 2015. Articulating "Archiannelids": Phylogenomics and Annelid Relationships, with Emphasis on Meiofaunal Taxa. Mol Biol Evol 32: 2860-2875.

Anstead CA, Korhonen PK, Young ND, Hall RS, Jex AR, Murali SC, Hughes DS, Lee SF, Perry T, Stroehlein AJ, Ansell BR, Breugelmans B et al. 2015. Lucilia cuprina genome unlocks parasitic fly biology to underpin future interventions. Nat Commun 6: 7344.

Babb PL, Lahens NF, Correa-Garhwal SM, Nicholson DN, Kim EJ, Hogenesch JB, Kuntner M, Higgins L, Hayashi CY, Agnarsson I, Voight BF. 2017. The Nephila clavipes genome highlights the diversity of spider silk genes and their complex expression. Nat Genet 49: 895-903.

Bailey AM, Posakony JW. 1995. Suppressor of Hairless directly activates transcription of Enhancer of split Complex genes in response to Notch receptor activity. Genes Dev 9: 26092622.

Baker CR, Booth LN, Sorrells TR, Johnson AD. 2012. Protein modularity, cooperative binding, and hybrid regulatory states underlie transcriptional network diversification. Cell 151: 80-95.

Baldwin-Brown JG, Weeks SC, Long AD. 2018. A New Standard for Crustacean Genomes: The Highly Contiguous, Annotated Genome Assembly of the Clam Shrimp Eulimnadia texana Reveals HOX Gene Order and Identifies the Sex Chromosome. Genome Biol Evol 10: 143-156.

Bang AG, Posakony JW. 1992. The Drosophila gene Hairless encodes a novel basic protein that controls alternative cell fates in adult sensory organ development. Genes Dev 6: 1752-1769. 
Barolo S, Posakony JW. 2002. Three habits of highly effective signaling pathways: principles of transcriptional control by developmental cell signaling. Genes Dev 16: 11671181.

Barolo S, Stone T, Bang AG, Posakony JW. 2002. Default repression and Notch signaling: Hairless acts as an adaptor to recruit the corepressors Groucho and dCtBP to Suppressor of Hairless. Genes Dev 16: 1964-1976.

Barreto FS, Pereira RJ, Burton RS. 2015. Hybrid dysfunction and physiological compensation in gene expression. Mol Biol Evol 32: 613-622.

Barreto FS, Watson ET, Lima TG, Willett CS, Edmands S, Li W, Burton RS. 2018. Genomic signatures of mitonuclear coevolution across populations of Tigriopus californicus. Nat Ecol Evol 2: 1250-1257.

Bast J, Schaefer I, Schwander T, Maraun M, Scheu S, Kraaijeveld K. 2016. No Accumulation of Transposable Elements in Asexual Arthropods. Mol Biol Evol 33: 697706.

Battelle BA, Ryan JF, Kempler KE, Saraf SR, Marten CE, Warren WC, Minx PJ, Montague MJ, Green PJ, Schmidt SA, Fulton L, Patel NH et al. 2016. Opsin Repertoire and Expression Patterns in Horseshoe Crabs: Evidence from the Genome of Limulus polyphemus (Arthropoda: Chelicerata). Genome Biol Evol 8: 1571-1589.

Bhambhani C, Chang JL, Akey DL, Cadigan KM. 2011. The oligomeric state of CtBP determines its role as a transcriptional co-activator and co-repressor of Wingless targets. EMBO J 30: 2031-2043.

Blankers T, Oh KP, Bombarely A, Shaw KL. 2018. The Genomic Architecture of a Rapid Island Radiation: Recombination Rate Variation, Chromosome Structure, and Genome Assembly of the Hawaiian Cricket Laupala. Genetics 209: 1329-1344.

Boratyn GM, Camacho C, Cooper PS, Coulouris G, Fong A, Ma N, Madden TL, Matten WT, McGinnis SD, Merezhuk Y, Raytselis Y, Sayers EW et al. 2013. BLAST: a more efficient report with usability improvements. Nucleic Acids Res 41: W29-33.

Brandt A, Schaefer I, Glanz J, Schwander T, Maraun M, Scheu S, Bast J. 2017. Effective purifying selection in ancient asexual oribatid mites. Nat Commun 8: 873.

Brauchle M, Bilican A, Eyer C, Bailly X, Martínez P, Ladurner P, Bruggmann R, Sprecher SG. 2018. Xenacoelomorpha Survey Reveals That All 11 Animal Homeobox Gene Classes Were Present in the First Bilaterians. Genome Biol Evol 10: 2205-2217.

Buchan DW, Minneci F, Nugent TC, Bryson K, Jones DT. 2013. Scalable web services for the PSIPRED Protein Analysis Workbench. Nucleic Acids Res 41: W349-57.

Bunnefeld L, Hearn J, Stone GN, Lohse K. 2018. Whole-genome data reveal the complex history of a diverse ecological community. Proc Natl Acad Sci U S A 115: E6507-E6515. 
Cao Z, Yu Y, Wu Y, Hao P, Di Z, He Y, Chen Z, Yang W, Shen Z, He X, Sheng J, Xu X et al. 2013. The genome of Mesobuthus martensii reveals a unique adaptation model of arthropods. Nat Commun 4: 2602.

Carmona-Antoñanzas G, Carmichael SN, Heumann J, Taggart JB, Gharbi K, Bron JE, Bekaert M, Sturm A. 2015. A Survey of the ATP-Binding Cassette (ABC) Gene Superfamily in the Salmon Louse (Lepeophtheirus salmonis). PLoS One 10: e0137394.

Chen W, Hasegawa DK, Kaur N, Kliot A, Pinheiro PV, Luan J, Stensmyr MC, Zheng Y, Liu W, Sun H, Xu Y, Luo Y et al. 2016. The draft genome of whitefly Bemisia tabaci MEAM1, a global crop pest, provides novel insights into virus transmission, host adaptation, and insecticide resistance. BMC Biol 14: 110.

Cheng T, Wu J, Wu Y, Chilukuri RV, Huang L, Yamamoto K, Feng L, Li W, Chen Z, Guo H, Liu J, Li S et al. 2017. Genomic adaptation to polyphagy and insecticides in a major East Asian noctuid pest. Nat Ecol Evol 1: 1747-1756.

Chipman AD, Ferrier DE, Brena C, Qu J, Hughes DS, Schröder R, Torres-Oliva M, Znassi N, Jiang H, Almeida FC, Alonso CR, Apostolou Z et al. 2014. The first myriapod genome sequence reveals conservative arthropod gene content and genome organisation in the centipede Strigamia maritima. PLoS Biol 12: e1002005.

Christie AE, Chi M, Lameyer TJ, Pascual MG, Shea DN, Stanhope ME, Schulz DJ, Dickinson PS. 2015. Neuropeptidergic Signaling in the American Lobster Homarus americanus: New Insights from High-Throughput Nucleotide Sequencing. PLoS One 10: e0145964.

Clarke TH, Garb JE, Hayashi CY, Arensburger P, Ayoub NA. 2015. Spider Transcriptomes Identify Ancient Large-Scale Gene Duplication Event Potentially Important in Silk Gland Evolution. Genome Biol Evol 7: 1856-1870.

Colbourne JK, Pfrender ME, Gilbert D, Thomas WK, Tucker A, Oakley TH, Tokishita S, Aerts A, Arnold GJ, Basu MK, Bauer DJ, Caceres CE et al. 2011. The ecoresponsive genome of Daphnia pulex. Science 331: 555-561.

Cong Q, Shen J, Li W, Borek D, Otwinowski Z, Grishin NV. 2017. The first complete genomes of Metalmarks and the classification of butterfly families. Genomics 109: 485493.

Dong X, Chaisiri K, Xia D, Armstrong SD, Fang Y, Donnelly MJ, Kadowaki T, McGarry JW, Darby AC, Makepeace BL. 2018. Genomes of trombidid mites reveal novel predicted allergens and laterally transferred genes associated with secondary metabolism. Gigascience 7: 1-33.

Douglas SE. 1995. DNA Strider. An inexpensive sequence analysis package for the Macintosh. Mol Biotechnol 3: 37-45.

Egekwu N, Sonenshine DE, Garman H, Barshis DJ, Cox N, Bissinger BW, Zhu J, M Roe R. 2016. Comparison of synganglion neuropeptides, neuropeptide receptors and 
neurotransmitter receptors and their gene expression in response to feeding in Ixodes scapularis (Ixodidae) vs. Ornithodoros turicata (Argasidae). Insect Mol Biol 25: 72-92.

Eyun SI, Soh HY, Posavi M, Munro JB, Hughes DST, Murali SC, Qu J, Dugan S, Lee SL, Chao H, Dinh H, Han Y et al. 2017. Evolutionary History of Chemosensory-Related Gene Families across the Arthropoda. Mol Biol Evol 34: 1838-1862.

Faddeeva-Vakhrusheva A, Derks MF, Anvar SY, Agamennone V, Suring W, Smit S, van Straalen NM, Roelofs D. 2016. Gene Family Evolution Reflects Adaptation to Soil Environmental Stressors in the Genome of the Collembolan Orchesella cincta. Genome Biol Evol 8: 2106-2117.

Fernández R, Edgecombe GD, Giribet G. 2016. Exploring Phylogenetic Relationships within Myriapoda and the Effects of Matrix Composition and Occupancy on Phylogenomic Reconstruction. Syst Biol 65: 871-889.

Fontana JR, Posakony JW. 2009. Both inhibition and activation of Notch signaling rely on a conserved Neuralized-binding motif in Bearded proteins and the Notch ligand Delta. Dev Biol 333: 373-385.

Francois CM, Duret L, Simon L, Mermillod-Blondin F, Malard F, Konecny-Dupré L, Planel R, Penel S, Douady CJ, Lefébure T. 2016. No Evidence That Nitrogen Limitation Influences the Elemental Composition of Isopod Transcriptomes and Proteomes. Mol Biol Evol 33: 2605-2620.

Fu X, Li J, Tian Y, Quan W, Zhang S, Liu Q, Liang F, Zhu X, Zhang L, Wang D, Hu J. 2017. Long-read sequence assembly of the firefly Pyrocoelia pectoralis genome. Gigascience 6: 1-7.

Fu Y, Yang Y, Zhang H, Farley G, Wang J, Quarles KA, Weng Z, Zamore PD. 2018. The genome of the Hi5 germ cell line from Trichoplusia ni, an agricultural pest and novel model for small RNA biology. Elife 7: e31628.

Fuzita FJ, Pinkse MW, Patane JS, Juliano MA, Verhaert PD, Lopes AR. 2015. Biochemical, transcriptomic and proteomic analyses of digestion in the scorpion Tityus serrulatus: insights into function and evolution of digestion in an ancient arthropod. PLoS One 10: e0123841.

Gompert Z, Comeault AA, Farkas TE, Feder JL, Parchman TL, Buerkle CA, Nosil P. 2014. Experimental evidence for ecological selection on genome variation in the wild. Ecol Lett 17: 369-379.

Gulia-Nuss M, Nuss AB, Meyer JM, Sonenshine DE, Roe RM, Waterhouse RM, Sattelle DB, de la Fuente J, Ribeiro JM, Megy K, Thimmapuram J, Miller JR et al. 2016. Genomic insights into the Ixodes scapularis tick vector of Lyme disease. Nat Commun 7: 10507.

Harrison MC, Jongepier E, Robertson HM, Arning N, Bitard-Feildel T, Chao H, Childers CP, Dinh H, Doddapaneni H, Dugan S, Gowin J, Greiner C et al. 2018. Hemimetabolous genomes reveal molecular basis of termite eusociality. Nat Ecol Evol 2: 557-566. 
Hase H, Koukai M, Hamanaka Y, Goto SG, Tachibana S, Shiga S. 2017. Transcriptome analysis of the brain under diapause and nondiapause conditions in the blowfly Protophormia terraenovae. Physiol Entomol 42: 282-289.

Holland PW, Marlétaz F, Maeso I, Dunwell TL, Paps J. 2017. New genes from old: asymmetric divergence of gene duplicates and the evolution of development. Philos Trans R Soc Lond B Biol Sci 372: 20150480.

Holt RA, Subramanian GM, Halpern A, Sutton GG, Charlab R, Nusskern DR, Wincker P, Clark AG, Ribeiro JM, Wides R, Salzberg SL, Loftus B et al. 2002. The genome sequence of the malaria mosquito Anopheles gambiae. Science 298: 129-149.

Hosono K, Sasaki T, Minoshima S, Shimizu N. 2004. Identification and characterization of a novel gene family YPEL in a wide spectrum of eukaryotic species. Gene 340: 31-43. Hoy MA, Waterhouse RM, Wu K, Estep AS, Ioannidis P, Palmer WJ, Pomerantz AF, Simão FA, Thomas J, Jiggins FM, Murphy TD, Pritham EJ et al. 2016. Genome Sequencing of the Phytoseiid Predatory Mite Metaseiulus occidentalis Reveals Completely Atomized Hox Genes and Superdynamic Intron Evolution. Genome Biol Evol 8: 1762-1775.

Hunt BJ, Özkaya Ö, Davies NJ, Gaten E, Seear P, Kyriacou CP, Tarling G, Rosato E. 2017. The Euphausia superba transcriptome database, SuperbaSE: An online, open resource for researchers. Ecol Evol 7: 6060-6077.

Husnik F, McCutcheon JP. 2016. Repeated replacement of an intrabacterial symbiont in the tripartite nested mealybug symbiosis. Proc Natl Acad Sci U S A 113: E5416-24. i5K C. 2013. The i5K Initiative: advancing arthropod genomics for knowledge, human health, agriculture, and the environment. J Hered 104: 595-600.

Ikeda KT, Hirose Y, Hiraoka K, Noro E, Fujishima K, Tomita M, Kanai A. 2015. Identification, expression, and molecular evolution of microRNAs in the "living fossil" Triops cancriformis (tadpole shrimp). RNA 21: 230-242.

Ioannidis P, Simao FA, Waterhouse RM, Manni M, Seppey M, Robertson HM, Misof B, Niehuis O, Zdobnov EM. 2017. Genomic Features of the Damselfly Calopteryx splendens Representing a Sister Clade to Most Insect Orders. Genome Biol Evol 9: 415430.

Jones DT, Cozzetto D. 2015. DISOPRED3: precise disordered region predictions with annotated protein-binding activity. Bioinformatics 31: 857-863.

Kelley JL, Peyton JT, Fiston-Lavier AS, Teets NM, Yee MC, Johnston JS, Bustamante CD, Lee RE, Denlinger DL. 2014. Compact genome of the Antarctic midge is likely an adaptation to an extreme environment. Nat Commun 5: 4611.

Kenny NJ, Chan KW, Nong W, Qu Z, Maeso I, Yip HY, Chan TF, Kwan HS, Holland PW, Chu KH, Hui JH. 2016. Ancestral whole-genome duplication in the marine chelicerate horseshoe crabs. Heredity (Edinb) 116: 190-199. 
Kirkness EF, Haas BJ, Sun W, Braig HR, Perotti MA, Clark JM, Lee SH, Robertson HM, Kennedy RC, Elhaik E, Gerlach D, Kriventseva EV et al. 2010. Genome sequences of the human body louse and its primary endosymbiont provide insights into the permanent parasitic lifestyle. Proc Natl Acad Sci U S A 107: 12168-12173.

Kjer KM, Simon C, Yavorskaya M, Beutel RG. 2016. Progress, pitfalls and parallel universes: a history of insect phylogenetics. J R Soc Interface 13: 20160363.

Kocot KM, Struck TH, Merkel J, Waits DS, Todt C, Brannock PM, Weese DA, Cannon JT, Moroz LL, Lieb B, Halanych KM. 2017. Phylogenomics of Lophotrochozoa with Consideration of Systematic Error. Syst Biol 66: 256-282.

Kono N, Nakamura H, Ito Y, Tomita M, Arakawa K. 2016. Evaluation of the impact of RNA preservation methods of spiders for de novo transcriptome assembly. Mol Ecol Resour 16: 662-672.

Lee BY, Kim HS, Hwang DS, Won EJ, Choi BS, Choi IY, Park HG, Rhee JS, Lee JS. 2015. Whole transcriptome analysis of the monogonont rotifer Brachionus koreanus provides molecular resources for developing biomarkers of carbohydrate metabolism. Comp Biochem Physiol Part D Genomics Proteomics 14: 33-41.

Lefébure T, Morvan C, Malard F, François C, Konecny-Dupré L, Guéguen L, WeissGayet M, Seguin-Orlando A, Ermini L, Sarkissian C, Charrier NP, Eme D et al. 2017. Less effective selection leads to larger genomes. Genome Res 27: 1016-1028.

Lemer S, Kawauchi GY, Andrade SC, González VL, Boyle MJ, Giribet G. 2015. Reevaluating the phylogeny of Sipuncula through transcriptomics. Mol Phylogenet Evol 83: 174-183.

Li S, Zhu S, Jia Q, Yuan D, Ren C, Li K, Liu S, Cui Y, Zhao H, Cao Y, Fang G, Li D et al. 2018. The genomic and functional landscapes of developmental plasticity in the American cockroach. Nat Commun 9: 1008.

Li ZQ, Zhang S, Ma Y, Luo JY, Wang CY, Lv LM, Dong SL, Cui JJ. 2013. First Transcriptome and Digital Gene Expression Analysis in Neuroptera with an Emphasis on Chemoreception Genes in Chrysopa pallens (Rambur). PLoS One 8: e67151.

Lou F, Gao T, Cai S, Han Z. 2018. De novo assembly and annotation of the whole transcriptome of Oratosquilla oratoria. Mar Genomics 38: 17-20.

Luo YJ, Kanda M, Koyanagi R, Hisata K, Akiyama T, Sakamoto H, Sakamoto T, Satoh N. 2018. Nemertean and phoronid genomes reveal lophotrochozoan evolution and the origin of bilaterian heads. Nat Ecol Evol 2: 141-151.

Luo YJ, Takeuchi T, Koyanagi R, Yamada L, Kanda M, Khalturina M, Fujie M, Yamasaki S, Endo K, Satoh N. 2015. The Lingula genome provides insights into brachiopod evolution and the origin of phosphate biomineralization. Nat Commun 6: 8301. 
Lynch M. 2007. The frailty of adaptive hypotheses for the origins of organismal complexity. Proc Natl Acad Sci USA 104 Suppl 1: 8597-8604.

Maier D. 2019. The evolution of transcriptional repressors in the Notch signaling pathway: a computational analysis. Hereditas 156: 5.

Maier D, Chen AX, Preiss A, Ketelhut M. 2008. The tiny Hairless protein from Apis mellifera: a potent antagonist of Notch signaling in Drosophila melanogaster. BMC Evol Biol 8: 175.

Maier D, Stumm G, Kuhn K, Preiss A. 1992. Hairless, a Drosophila gene involved in neural development, encodes a novel, serine rich protein. Mech Dev 38: 143-156.

Marck C. 1988. 'DNA Strider': a 'C' program for the fast analysis of DNA and protein sequences on the Apple Macintosh family of computers. Nucleic Acids Res 16: 1829-1836.

Mathers TC, Chen Y, Kaithakottil G, Legeai F, Mugford ST, Baa-Puyoulet P, Bretaudeau A, Clavijo B, Colella S, Collin O, Dalmay T, Derrien T et al. 2017. Rapid transcriptional plasticity of duplicated gene clusters enables a clonally reproducing aphid to colonise diverse plant species. Genome Biol 18: 27.

Millard CJ, Fairall L, Schwabe JW. 2014. Towards an understanding of the structure and function of MTA1. Cancer Metastasis Rev 33: 857-867.

Millard CJ, Watson PJ, Celardo I, Gordiyenko Y, Cowley SM, Robinson CV, Fairall L, Schwabe JW. 2013. Class I HDACs share a common mechanism of regulation by inositol phosphates. Mol Cell 51: 57-67.

Miller JR, Koren S, Dilley KA, Harkins DM, Stockwell TB, Shabman RS, Sutton GG. 2018. A draft genome sequence for the Ixodes scapularis cell line, ISE6. F1000Res 7: 297.

Miller SW, Rebeiz M, Atanasov JE, Posakony JW. 2014. Neural precursor-specific expression of multiple Drosophila genes is driven by dual enhancer modules with overlapping function. Proc Natl Acad Sci USA 111: 17194-17199.

Misof B, Liu S, Meusemann K, Peters RS, Donath A, Mayer C, Frandsen PB, Ware J, Flouri T, Beutel RG, Niehuis O, Petersen M et al. 2014. Phylogenomics resolves the timing and pattern of insect evolution. Science 346: 763-767.

Nibu Y, Zhang H, Levine M. 1998. Interaction of short-range repressors with Drosophila CtBP in the embryo. Science 280: 101-104.

Niehuis O, Hartig G, Grath S, Pohl H, Lehmann J, Tafer H, Donath A, Krauss V, Eisenhardt C, Hertel J, Petersen M, Mayer C et al. 2012. Genomic and morphological evidence converge to resolve the enigma of Strepsiptera. Curr Biol 22: 1309-1313.

Nossa CW, Havlak P, Yue JX, Lv J, Vincent KY, Brockmann HJ, Putnam NH. 2014. Joint assembly and genetic mapping of the Atlantic horseshoe crab genome reveals ancient whole genome duplication. Gigascience 3: 9. 
Oxley PR, Ji L, Fetter-Pruneda I, McKenzie SK, Li C, Hu H, Zhang G, Kronauer DJ. 2014. The genome of the clonal raider ant Cerapachys biroi. Curr Biol 24: 451-458.

Papanicolaou A, Schetelig MF, Arensburger P, Atkinson PW, Benoit JB, Bourtzis K, Castañera P, Cavanaugh JP, Chao H, Childers C, Curril I, Dinh H et al. 2016. The whole genome sequence of the Mediterranean fruit fly, Ceratitis capitata (Wiedemann), reveals insights into the biology and adaptive evolution of a highly invasive pest species. Genome Biol 17: 192.

Poynton HC, Hasenbein S, Benoit JB, Sepulveda MS, Poelchau MF, Hughes DST, Murali SC, Chen S, Glastad KM, Goodisman MAD, Werren JH, Vineis JH et al. 2018. The Toxicogenome of Hyalella azteca: A Model for Sediment Ecotoxicology and Evolutionary Toxicology. Environ Sci Technol 52: 6009-6022.

Rebeiz M, Posakony JW. 2004. GenePalette: A universal software tool for genome sequence visualization and analysis. Dev Biol 271: 431-438.

Regier JC, Shultz JW, Zwick A, Hussey A, Ball B, Wetzer R, Martin JW, Cunningham CW. 2010. Arthropod relationships revealed by phylogenomic analysis of nuclear protein-coding sequences. Nature 463: 1079-1083.

Rehan SM, Glastad KM, Lawson SP, Hunt BG. 2016. The Genome and Methylome of a Subsocial Small Carpenter Bee, Ceratina calcarata. Genome Biol Evol 8: 1401-1410. Rider SD, Morgan MS, Arlian LG. 2015. Draft genome of the scabies mite. Parasit Vectors 8: 585 .

Rosenfeld JA, Reeves D, Brugler MR, Narechania A, Simon S, Durrett R, Foox J, Shianna K, Schatz MC, Gandara J, Afshinnekoo E, Lam ET et al. 2016. Genome assembly and geospatial phylogenomics of the bed bug Cimex lectularius. Nat Commun 7: 10164.

Roxström-Lindquist K, Faye I. 2001. The Drosophila gene Yippee reveals a novel family of putative zinc binding proteins highly conserved among eukaryotes. Insect Mol Biol 10: 77-86.

Sahoo PK, Kar B, Mohapatra A, Mohanty J. 2013. De novo whole transcriptome analysis of the fish louse, Argulus siamensis: first molecular insights into characterization of Toll downstream signalling molecules of crustaceans. Exp Parasitol 135: 629-641.

Sanggaard KW, Bechsgaard JS, Fang X, Duan J, Dyrlund TF, Gupta V, Jiang X, Cheng L, Fan D, Feng Y, Han L, Huang Z et al. 2014. Spider genomes provide insight into composition and evolution of venom and silk. Nat Commun 5: 3765.

Sasaki M, Akiyama-Oda Y, Oda H. 2017. Evolutionary origin of type IV classical cadherins in arthropods. BMC Evol Biol 17: 142.

Schwager EE, Sharma PP, Clarke T, Leite DJ, Wierschin T, Pechmann M, Akiyama-Oda Y, Esposito L, Bechsgaard J, Bilde T, Buffry AD, Chao H et al. 2017. The house spider 
genome reveals an ancient whole-genome duplication during arachnid evolution. BMC Biol 15: 62.

Shen J, Cong Q, Kinch LN, Borek D, Otwinowski Z, Grishin NV. 2016. Complete genome of Pieris rapae, a resilient alien, a cabbage pest, and a source of anti-cancer proteins. F1000Res 5: 2631.

Sikkink KL, Kobiela ME, Snell-Rood EC. 2017. Genomic adaptation to agricultural environments: cabbage white butterflies (Pieris rapae) as a case study. BMC Genomics 18: 412.

Simakov O, Kawashima T, Marlétaz F, Jenkins J, Koyanagi R, Mitros T, Hisata K, Bredeson J, Shoguchi E, Gyoja F, Yue JX, Chen YC et al. 2015. Hemichordate genomes and deuterostome origins. Nature 527: 459-465.

Simakov O, Marletaz F, Cho SJ, Edsinger-Gonzales E, Havlak P, Hellsten U, Kuo DH, Larsson T, Lv J, Arendt D, Savage R, Osoegawa K et al. 2013. Insights into bilaterian evolution from three spiralian genomes. Nature 493: 526-531.

Simon S, Blanke A, Meusemann K. 2018. Reanalyzing the Palaeoptera problem - The origin of insect flight remains obscure. Arthropod Struct Dev 47: 328-338.

Smith AF, Posakony JW, Rebeiz M. 2017. Automated tools for comparative sequence analysis of genic regions using the GenePalette application. Dev Biol 429: 158-164.

Song H, Hasson P, Paroush Z, Courey AJ. 2004. Groucho oligomerization is required for repression in vivo. Mol Cell Biol 24: 4341-4350.

Techer MA, Rane RV, Grau ML, Roberts JMK, Sullivan ST, Liachko I, Childers AK, Evans JD, Mikheyev AS. 2019. Genomic analyses of sibling honey bee ectoparasitic mite species show divergent strategies of adaptation. bioRxiv doi: 10.1101/512988.

Tribolium GSC, Richards S, Gibbs RA, Weinstock GM, Brown SJ, Denell R, Beeman RW, Gibbs R, Beeman RW, Brown SJ, Bucher G, Friedrich M et al. 2008. The genome of the model beetle and pest Tribolium castaneum. Nature 452: 949-955.

True JR, Haag ES. 2001. Developmental system drift and flexibility in evolutionary trajectories. Evol Dev 3: 109-119.

von Reumont BM, Campbell LI, Richter S, Hering L, Sykes D, Hetmank J, Jenner RA, Bleidorn C. 2014. A Polychaete's powerful punch: venom gland transcriptomics of Glycera reveals a complex cocktail of toxin homologs. Genome Biol Evol 6: 2406-2423.

Werren JH, Richards S, Desjardins CA, Niehuis O, Gadau J, Colbourne JK, Werren JH, Richards S, Desjardins CA, Niehuis O, Gadau J, Colbourne JK et al. 2010. Functional and evolutionary insights from the genomes of three parasitoid Nasonia species. Science 327: 343-348. 
Whelan NV, Kocot KM, Santos SR, Halanych KM. 2014. Nemertean toxin genes revealed through transcriptome sequencing. Genome Biol Evol 6: 3314-3325.

Wu C, Jordan MD, Newcomb RD, Gemmell NJ, Bank S, Meusemann K, Dearden PK, Duncan EJ, Grosser S, Rutherford K, Gardner PP, Crowhurst RN et al. 2017a. Analysis of the genome of the New Zealand giant collembolan (Holacanthella duospinosa) sheds light on hexapod evolution. BMC Genomics 18: 795.

Wu C, Twort VG, Crowhurst RN, Newcomb RD, Buckley TR. 2017b. Assembling large genomes: analysis of the stick insect (Clitarchus hookeri) genome reveals a high repeat content and sex-biased genes associated with reproduction. BMC Genomics 18: 884.

Yuan Z, Praxenthaler H, Tabaja N, Torella R, Preiss A, Maier D, Kovall RA. 2016. Structure and Function of the $\mathrm{Su}(\mathrm{H})$-Hairless Repressor Complex, the Major Antagonist of Notch Signaling in Drosophila melanogaster. PLoS Biol 14: e1002509.

Zacharioudaki E, Falo Sanjuan J, Bray S. 2019. Mi-2/NuRD complex protects stem cell progeny from mitogenic Notch signaling. Elife 8: e41637.

Zhang G, Fang X, Guo X, Li L, Luo R, Xu F, Yang P, Zhang L, Wang X, Qi H, Xiong Z, Que $\mathrm{H}$ et al. 2012. The oyster genome reveals stress adaptation and complexity of shell formation. Nature 490: 49-54.

Zhao C, Escalante LN, Chen H, Benatti TR, Qu J, Chellapilla S, Waterhouse RM, Wheeler D, Andersson MN, Bao R, Batterton M, Behura SK et al. 2015. A massive expansion of effector genes underlies gall-formation in the wheat pest Mayetiola destructor. Curr Biol 25: 613-620. 
Table 1. Co-repressor recruitment motifs in protostome $\mathrm{Su}(\mathrm{H})$ proteins

Species

Ecdyonurus insignis

Calopteryx splendens

Machilis hrabei

Catajapyx aquilonaris

Holacanthella duospinosa

Pollicipes pollicipes

Hyalella azteca

Eurytemora affinis

Triops cancriformis

Argulus siamensis

Strigamia maritima

Metaseiulus occidentalis

Ixodes scapularis

Parasteatoda tepidariorum 1

Parasteatoda tepidariorum 2

Limulus polyphemus 1

Limulus polyphemus 2

Centruroides sculpturatus

Euperipatoides kanangrensis

Glycera dibranchiata

Nephasoma pellucidum

Owenia sp.

Octopus bimaculoides

Crassostrea gigas

Lottia gigantea

Notospermus geniculatus

Malacobdella grossa

Lingula anatina

Phoronis australis

Procotyla fluviatilis*

Brachionus koreanus

Xenoturbella bocki
Atelura formicaria

Naineris dendritica
CtBP motif

YPDNHPVDLSSPRPH

YTDNHPVDLSSPRPP

YPDNHPVDLSSPRPQ

YPDNHPVDLSSPRPH

STANNPVDLSSPRGS

VPNSNPVDLSNPSPS

YPDNHPVDLSSPRPE

SLGHRPVDLSQAPSP

SETSAPVDLSAPRPN

HPEARPVDLSSSRLL

YPENNPVDLSNSRTG

FADNHPVDLSNSHRG

GADRKPLDMSAAHRS

QAAGAPVDMSSHPAR

VIDSHPVDLSSPKPS

RYEGRPVDLSSPRPN

PYDGHPVDLSNQRPD

TYESHPVDLSNQRPD

GYESSPVDLSSHRSV

NSYDNPVDLSSHRSS

DPNGHPVDLSHSRHI

APYDDPVDLSSRHPA

AGYETPVDLSSPRPC

QPYENPVDLSRRHIK

NGFDNPMDLSNGKVV

GGYENPMDLSSNKPG

AGVENPVDLSNGRIS

VQYDNPIDLSNRLEG

LHYDNPLDLTNRLDE

GGYENPMDLSRRTEM

QHDNRPMDLSSRGOH

ETLFEPLDLRSPIGV

AKDETPIDLSSKKSK

KRYSAPLNLTVHDKC
Gro motif

Source

APMIPGSLTPPDKMNGEHPHHG

HHMIPGSLTPPDKMNGEHPAMH

PHMIPGSLTPPDKMNGEHPHHS

PHMLPGSLTPPDKMNGEHPHHG

APMIPGSLTPPDKVNGEHHSHH

SNFVPGSLSPPERMNGNDPSLL

GPLIAGSLTPPDKLGAELGLHA

AAMLAGSLTPPDKLNSDPQQQQ

YGMLPGSLTPPDKLNGDHCSPG

YHSSSLTLTPPDKVNVDGSNSQ

SPMIPGSLTPPDKMNGEHHPGH

SHMIAGSLTPPDKVNGEHGHOL

$\begin{array}{ll} & 13 \\ & 14 \\ & 15 \\ & 16 \\ & 17 \\ & 18 \\ \text { MQLISGSMTSHDKVNGDQHSLG } & 19 \\ \text { QQILPGSLGPSDKVNGDLVSLA } & 20 \\ \text { PHMIHGSLTPPDRVNGEPGSGL } & 21 \\ \text { GHMIPGTLTPPDKLNGDHHHHH } & 22 \\ \text { SHLIPGSLTPPDKINGEGITTS } & 23 \\ \text { AHLIPGSLTPPDKINGDMVTMA } & 24 \\ \text { HLMPAGSLTPPDKISGDSISMA } & 25 \\ \text { SHIVAGSLTPPEKINGDPGAMA } & 26 \\ \text { SHLFTGSLTPPEKPNGDLVPMS } & 27 \\ \text { NHMIPGSLTPPDKVNGDMVPLP } & 28 \\ \text { GSGIAGSMTPPDGGKGNDLDLQ } & 29 \\ \text { AHMIPGNLTPPDKVNGEMVPMA } & 30 \\ \text { SHLIAGSLTPPDKVNGDVVSMA } & 31 \\ & 32 \\ & 33 \\ \text { DVRVLGRLTPPDKOHVNNDVGA } & 34\end{array}$

Shown are alignments of short linear amino acid motifs (bold) in the N-terminal region

of $\mathrm{Su}(\mathrm{H})$ proteins that mediate direct recruitment of the co-repressors CtBP and Gro.

Numbers in the column at right refer to the source of the corresponding sequence data, with accession numbers and publication citations indicated (see list below).

1 GCCL01029953.1 (Simon et al. 2018)

2 LYUA01002621.1 (Ioannidis et al. 2017)

3 GAYJ02050375.1 (Misof et al. 2014) 


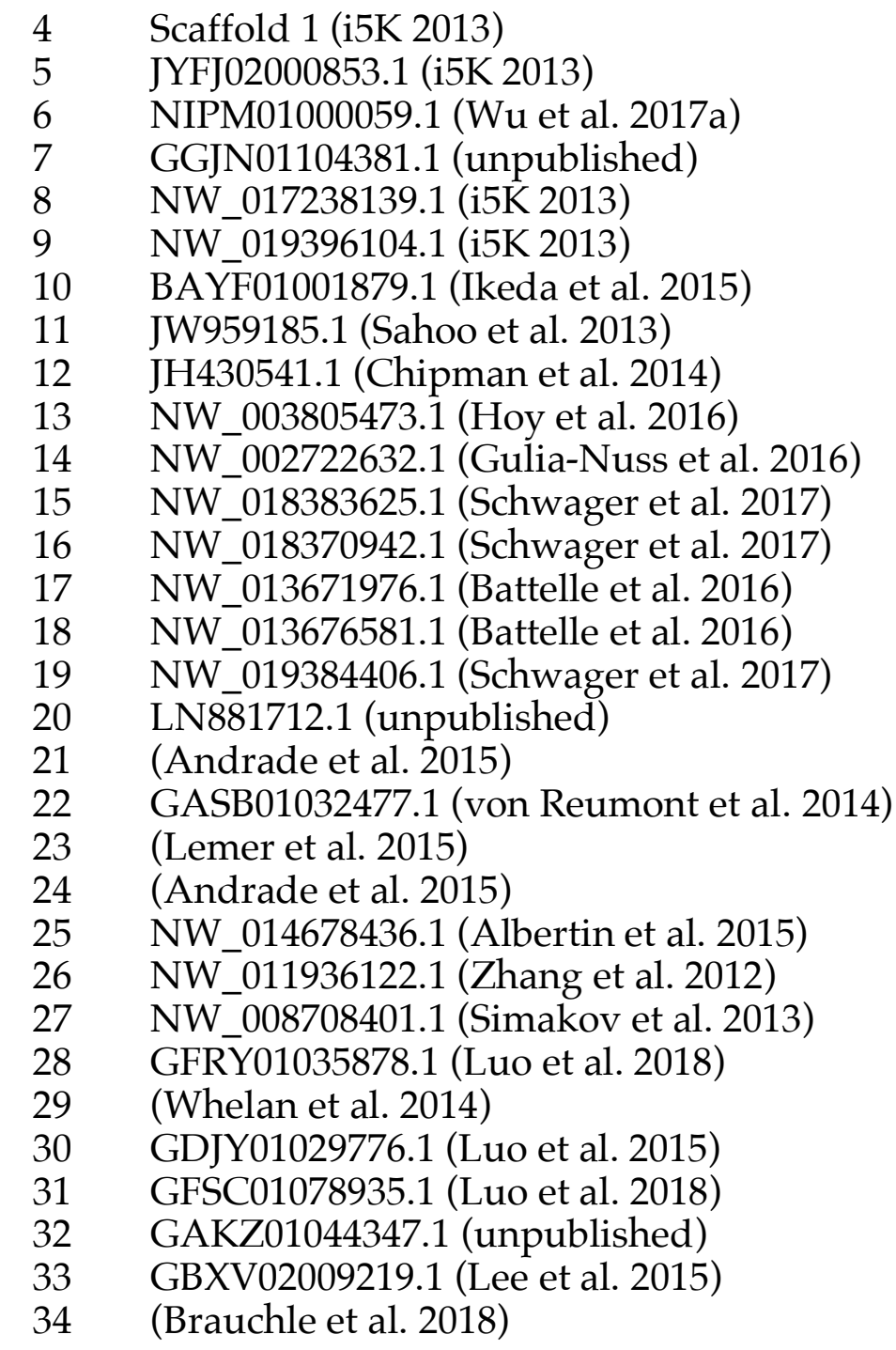




\section{Figure legends}

Figure 1. Hairless mediates indirect recruitment of co-repressor proteins to $\mathrm{Su}(\mathrm{H})$. (A) Diagram denoting locations of conserved domains and motifs within Hairless, and illustrating extreme size differences of the protein in different species. Shown is Hairless from the carpenter bee Ceratina calcarata and the blowfly Protophormia terraenovae (Hase et al. 2017), with scale and protein sizes indicated. (B) Summary of Hairless's mode of action as an adaptor protein that recruits the global co-repressors Cterminal Binding Protein (CtBP) and Groucho (Gro) to Suppressor of Hairless [Su(H)], the transducing transcription factor for the Notch $(\mathrm{N})$ cell-cell signaling pathway (Barolo et al. 2002). In the absence of signaling through the Notch receptor (left), $\mathrm{Su}(\mathrm{H})$ acts as a repressor of Notch target genes, despite the presence of transcriptional activator proteins (orange oval). Upon activation of the Notch receptor (middle), $\mathrm{Su}(\mathrm{H})$, in a complex with the receptor's intracellular domain (NICD) and the co-activator Mastermind (Mam), functions to activate transcription of pathway target genes in cooperation with other transcriptional activators. In the absence of Hairless and hence in the absence of $\mathrm{Su}(\mathrm{H})^{\prime} \mathrm{s}$ repressive activity (right), the partner transcription factors are often sufficient to activate expression of target genes in a signal-independent manner (Barolo and Posakony 2002).

Figure 1-figure supplement 1. Graph showing predicted disordered regions in Drosophila melanogaster Hairless, generated by DISOPRED3 (Buchan et al. 2013; Jones and Cozzetto 2015). Locations of the Gro-binding motif (purple arrow) and CtBPbinding motif (red arrow) are indicated. Note that most of the region between these two motifs is strongly predicted to be disordered. 
Figure 2. Phylogenetic distribution of Hairless and related S-CAP proteins. (A) Based on extensive BLAST searches of available genome and transcriptome assemblies, orthologs of the canonical Hairless gene are found only in the Pancrustacea (blue bar), while orthologs of a gene that encodes the related S-CAP protein are found in the Myriapods (mS-CAP, red bar) and Chelicerates (cS-CAP, pink bar). We suggest S-CAP as a suitable umbrella nomenclature for this gene family (black bracket). Tree adapted from Figure 2 of Regier et al. (Regier et al. 2010). (B) Consistent with the presence of Hairless as an adaptor protein, $\mathrm{Su}(\mathrm{H})$ in most insect orders (the Neoptera clade) has lost the ancestral short linear motifs that mediate direct recruitment of the CtBP and Gro corepressor proteins (red bar). However, in the Crustacea, Collembola, Diplura, and a subset of Insecta, the ancestral recruitment motifs have been retained in $\mathrm{Su}(\mathrm{H})$, despite the presence of Hairless (see Table 1 and Supplementary file 3). Tree adapted from Misof et al. (Misof et al. 2014) and Kjer et al. (Kjer et al. 2016).

Figure 3. Direct binding of co-repressor proteins by $\mathrm{Su}(\mathrm{H})$ from the centipede Strigamia maritima. (A) The PVDLS motif in the N-terminal region of $\mathrm{Su}(\mathrm{H})$ from the centipede Strigamia maritima directly binds Drosophila CtBP. A His-tagged 116-aa segment of the Strigamia $\mathrm{Su}(\mathrm{H})$ protein, bearing a PVDLS recruitment motif for $\mathrm{CtBP}$, binds strongly to GST-dCtBP (WT, lane 2). Mutation of the motif to alanines (AAAAA) abolishes this interaction (PVDLSmut, lane 1). (B) The conserved GSLTPPDKV motif in the Nterminal region of Strigamia $\mathrm{Su}(\mathrm{H})$ directly binds Drosophila Gro. His-tagged E(spl)m $\beta$ HLH protein, which bears a C-terminal WRPW motif that recruits Gro, is used as a binding control. Wild-type (WT) HLHm $\beta$ binds GST-Gro (lane 2), while a truncated 
version of the protein lacking the WRPW motif (lane 1) fails to bind. A synthetic version of HLHm $\beta$ in which the WRPW motif has been replaced by the wild-type GSLTPPDKV motif also binds GST-Gro efficiently (lane 4), while a mutant version in which GSLTPPDKV is replaced by alanines (AAAAAAAAA) shows extremely weak binding (lane 3). No binding of any of the His-tagged proteins to GST alone is observed, even with substantially greater amounts of GST compared to GST-Gro.

Figure 4. S-CAP proteins in Myriapods and Chelicerates contain a Hairless-like domain that binds $\mathrm{Su}(\mathrm{H})$. (A) Alignment of the Suppressor of Hairless Binding Domain (SBD) in Drosophila melanogaster (Dmel) Hairless with the related motif in the S-CAP proteins from a representative set of Myriapods and Chelicerates. Numbers flanking each sequence segment represent amino acid positions within the protein. The contiguous SBD motif is highlighted in bold. Pairwise amino acid sequence identities within the motifs are indicated by vertical lines; conservative substitutions are indicated by + signs. Amino acids in Hairless that have been shown to make direct contact with $\mathrm{Su}(\mathrm{H})$ [including the non-contiguous tryptophan (W) residue] (Yuan et al. 2016) are highlighted in red. Hydrophobic residues nearly always found immediately adjacent to the $\mathrm{W}$ are underlined. Species names are as follows: Smar (Strigamia maritima) [see also (Maier 2019)]; Hsub (Hydroschendyla submarina) (Fernández et al. 2016); Agir (Anopsobius giribeti) (Fernández et al. 2016); Ptep (Parasteatoda tepidariorum); Hruf (Hypochthonius rufulus) (Bast et al. 2016); Ssca (Sarcoptes scabiei); Vjac (Varroa jacobsoni) (Techer et al. 2019); Iper (Ixodes persulcatus); Mmar (Mesobuthus martensii) (Cao et al. 2013); Lpol (Limulus polyphemus). (B) SBD motifs in both Hairless and S-CAP proteins (red) are encoded in two exons with the same splice junction (indicated by /; see grey highlight). 
Pairwise amino acid sequence identities within the motifs are indicated by vertical lines; conservative substitutions are indicated by + signs. Species names as in A, except for Isca (Ixodes scapularis). (C) Spider S-CAP protein binds directly to Drosophila Su(H) in vitro. In all panels, lanes 1-4 represent the indicated His-tagged segments of wild-type Drosophila (Dmel) Hairless (lane 1); Dmel Hairless bearing alanine substitutions for each of five SBD residues shown to contact $\mathrm{Su}(\mathrm{H})$ (lane 2); wild-type S-CAP from the spider Parasteatoda tepidariorum (Ptep) (lane 3); Ptep S-CAP bearing the same five alanine substitutions (lane 4). Input levels of these His-tagged proteins for each experiment are shown in the respective "input" panels. Remaining two panels show the results of pulldown assays using Sepharose beads bearing only GST (left side) or GST-Su(H) (right side). Left: No binding of the His-tagged proteins to GST alone is observed. Right: Wild-type Dmel Hairless binds efficiently to GST-Su(H) (lane 1); this interaction is severely reduced by the introduction of the five alanine substitutions (lane 2). Wildtype Ptep S-CAP likewise binds to GST-Su(H) (lane 3), while no binding is observed with the alanine-substitution mutant (lane 4); the same result is obtained even when the amount of input Ptep S-CAPs (wild-type and mutant) is increased by a factor of 10 (lanes 3 and 4, 10X). Amounts of GST and GST-Su(H) on the beads are shown in the Coomassie stains below the corresponding pulldown lanes.

Figure 5. Sequence characteristics of S-CAP proteins in Myriapods and Chelicerates. (A) Diagrams of representative examples of Myriapod and Chelicerate S-CAP proteins, denoting locations of SBD motifs and CtBP recruitment motifs. Scale and protein sizes are indicated. (B) Chelicerate, but not Myriapod, S-CAP proteins share N-terminal ELM2 and SANT domains with an MTA zinc-finger protein from the same species. Scale and protein sizes are indicated. (C) Shared ELM2 and SANT domains in 
Chelicerate MTA and S-CAP proteins are encoded in two exons with the same splice junction (indicated by /; red arrows). Pairwise amino acid sequence identities within the motifs are indicated by vertical lines; conservative substitutions are indicated by + signs. Species names as in Figure 4A.

Figure 5-figure supplement 1. Alignments of sequence regions shared by representative S-CAP proteins from (A) Chelicerates and (B) Myriapods. Amino acids at the ends of the aligned sequences are numbered. Pairwise amino acid sequence identities are indicated by vertical lines; conservative substitutions are indicated by + signs. ELM2 and SANT domains found in Chelicerate S-CAPs (A) are highlighted in colors corresponding to those in Figure 5B. Species names are as follows: (A) Hruf (Hypochthonius rufulus), Lpol (Limulus polyphemus), Otur (Ornithodoros turicata) (Egekwu et al. 2016), Tser (Tityus serrulatus) (Fuzita et al. 2015), Lhes (Latrodectus hesperus) (Clarke et al. 2015); (B) Smar (Strigamia maritima), Agir (Anopsobius giribeti).

Figure 6. Genes encoding both Hairless and S-CAP proteins are frequently located immediately adjacent to an MTA gene. Separate scale for each diagram is shown at the left. Three examples are shown for Hairless: the carpenter bee Ceratina calcarata (Ccal), the wheat aphid Schizaphis graminum (Sgra) (QEWZ01001380.1), and the lady beetle Harmonia axyridis (Haxy). Note that microsynteny is often preserved even when gene locations and relative orientations are changed. One example each is shown for S-CAP in Myriapods [the centipede Strigamia maritima (Smar)] and Chelicerates [the house spider Parasteatoda tepidariorum (Ptep)]. See also Supplementary file 1 and Supplementary file 4 . 
Figure 7. Speculative possible sources for key elements of the Hairless and S-CAP proteins. (A) A C-terminal segment of the highly conserved Yippee-like protein (Roxström-Lindquist and Faye 2001; Hosono et al. 2004) is closely related to the Cterminal half of Hairless and S-CAP SBDs. Upper diagram is a sequence alignment of the entire Yippee-like proteins from Drosophila melanogaster (Dm) and Homo sapiens (Hs). Aligned below are contiguous SBD motifs from Drosophila Hairless and five Myriapod and Chelicerate S-CAPs; their C-terminal halves are shown in bold. Two leucine (L) residues shown to make direct contact with $\mathrm{Su}(\mathrm{H})$ (Yuan et al. 2016) are highlighted in red. Amino acid sequence identities are indicated by vertical lines; conservative substitutions are indicated by + signs. Other species names as in Figure 4A. (B) As shown in the gene diagram at the bottom, the CtBP recruitment motif in Hairless is encoded by a very small exon located at the extreme $3^{\prime}$ end of the gene [example is from the Oriental fruit fly Bactrocera dorsalis (Bdor; JFBF01000273.1); scale indicated]. A preexisting gene encoding a protein that utilizes the same PLNLS recruitment motif is a possible source of this exon. Example shown is a portion of the senseless gene from the red flour beetle Tribolium castaneum (Tribolium et al. 2008). Senseless directly recruits the CtBP co-repressor via the PLNLS motif (Miller et al. 2014). This portion of the protein is encoded in exon 2; splice junction is indicated by a red /. Aligned beneath it is the last exon of the Bdor Hairless gene, illustrating its splice junction in the same frame as senseless exon 2. 


\section{Supplementary file legends}

Supplementary file 1. Representative catalog of Hairless proteins in the Pancrustacea, selected from a curated collection of approximately 400 full-length sequences. Annotated sequences of the entries in this list are provided in Supplementary file 2. In the "MTA microsynteny?" column, + and - in parentheses denote the relative orientation of the Hairless and MTA genes in the genome.

Supplementary file 2. Annotated FASTA file of sequences of the Hairless proteins included in Supplementary file 1. Characteristic conserved domains and motifs are colored as in Figure 1A.

Supplementary file 3. Annotated FASTA file of sequences of the $\mathrm{Su}(\mathrm{H})$ proteins included in Table 1; species for which a full-length $\mathrm{Su}(\mathrm{H})$ sequence is not available are omitted here. Colors denote conserved sequence features. Motifs for direct recruitment of the CtBP and Gro co-repressor proteins (aligned in Table 1) are shown in red and green, respectively. Large region highlighted in orange is the highly conserved body of $\mathrm{Su}(\mathrm{H})$, extending from "LTREAM" to "YTPEP".

Supplementary file 4. Representative catalog of S-CAP proteins in the Myriapoda and Chelicerata, selected from a curated collection of approximately 50 full-length sequences. Annotated sequences of the entries in this list are provided in Supplementary file 5. In the "MTA microsynteny?" column, + and - in parentheses denote the relative orientation of the S-CAP and MTA genes in the genome. The " $\mathrm{H}$ SBD splice?" column indicates whether the Su(H)-binding domain (SBD) in the listed 
protein is encoded by two exons with the same splice junction as in Hairless. If not, the alternative exon structure is indicated.

Supplementary file 5. Annotated FASTA file of sequences of the S-CAP proteins included in Supplementary file 4. Characteristic domains and motifs are colored as follows: $\mathrm{Su}(\mathrm{H})$-binding domain $(\mathrm{SBD})$, orange; $\mathrm{CtBP}$ recruitment motifs, red. 


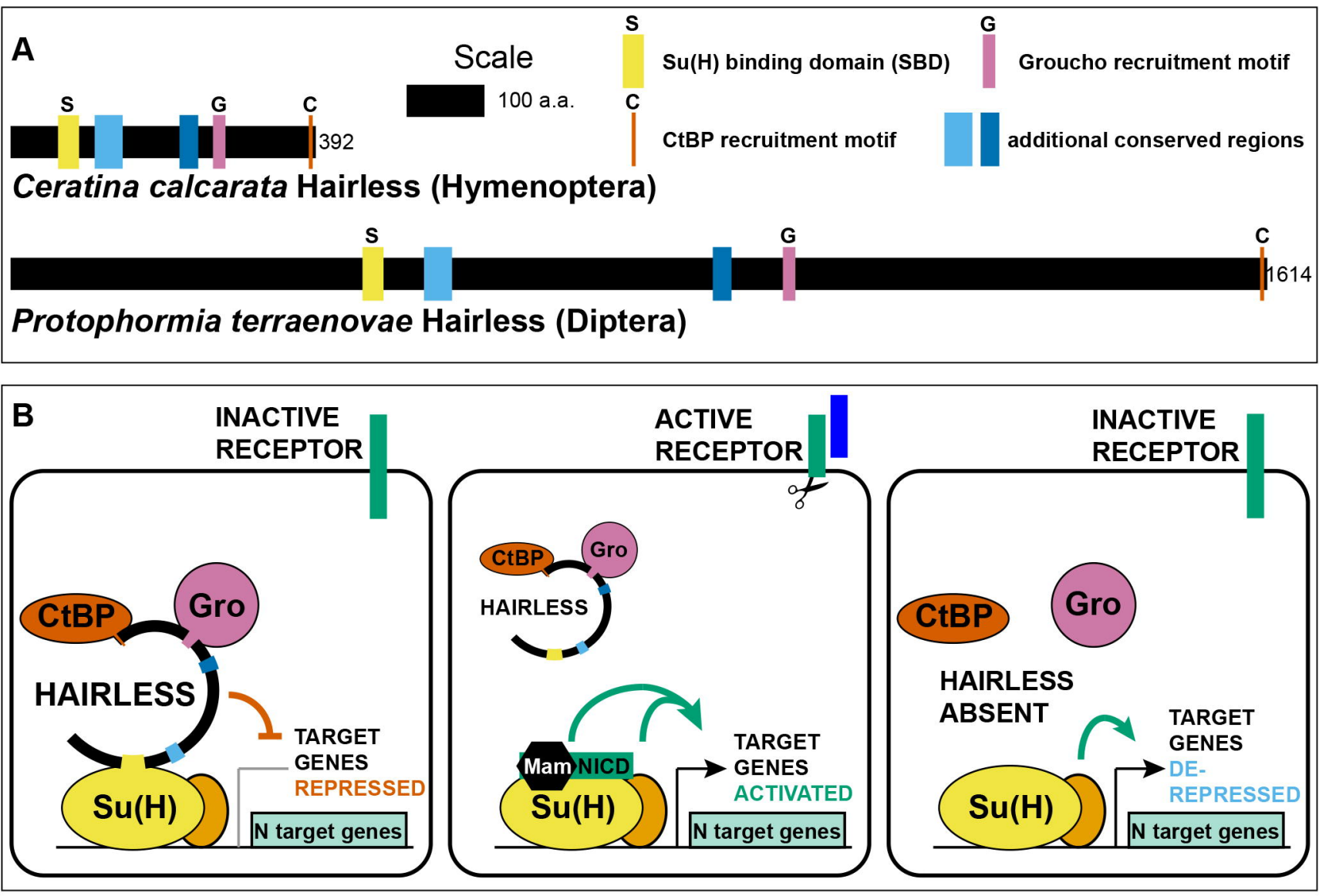


A

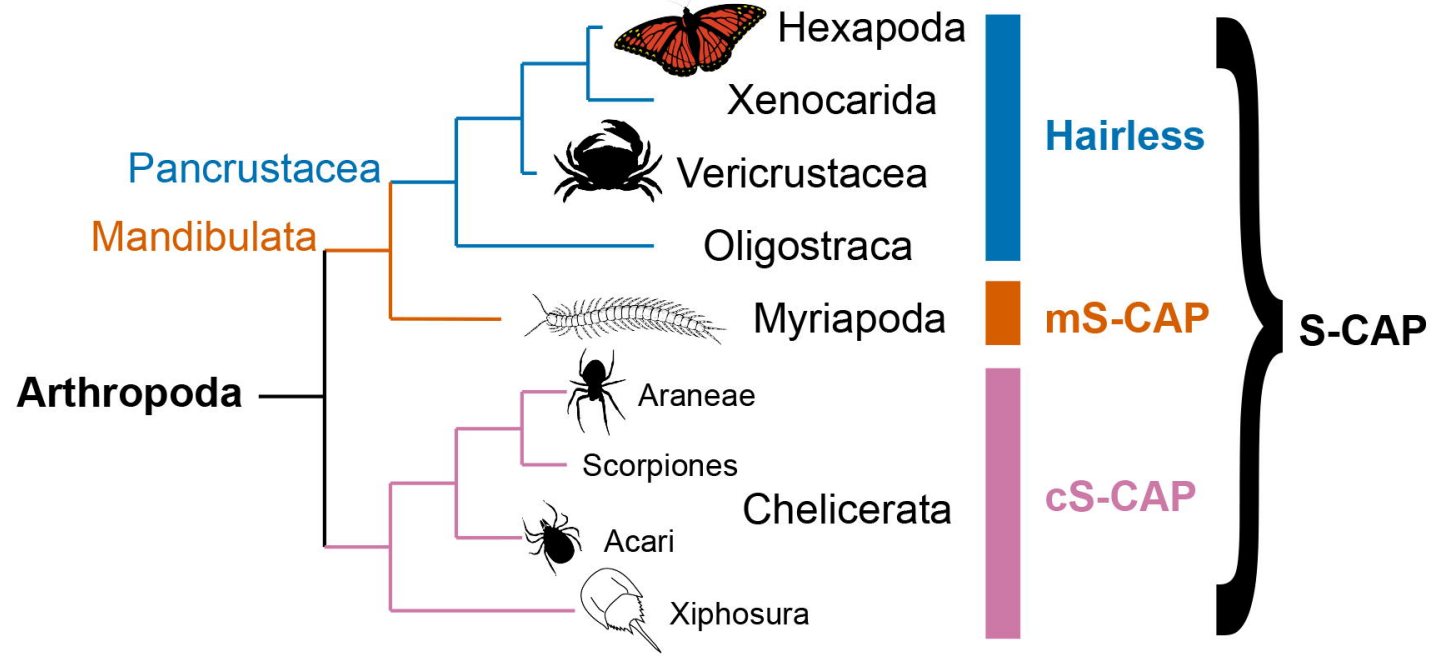

B

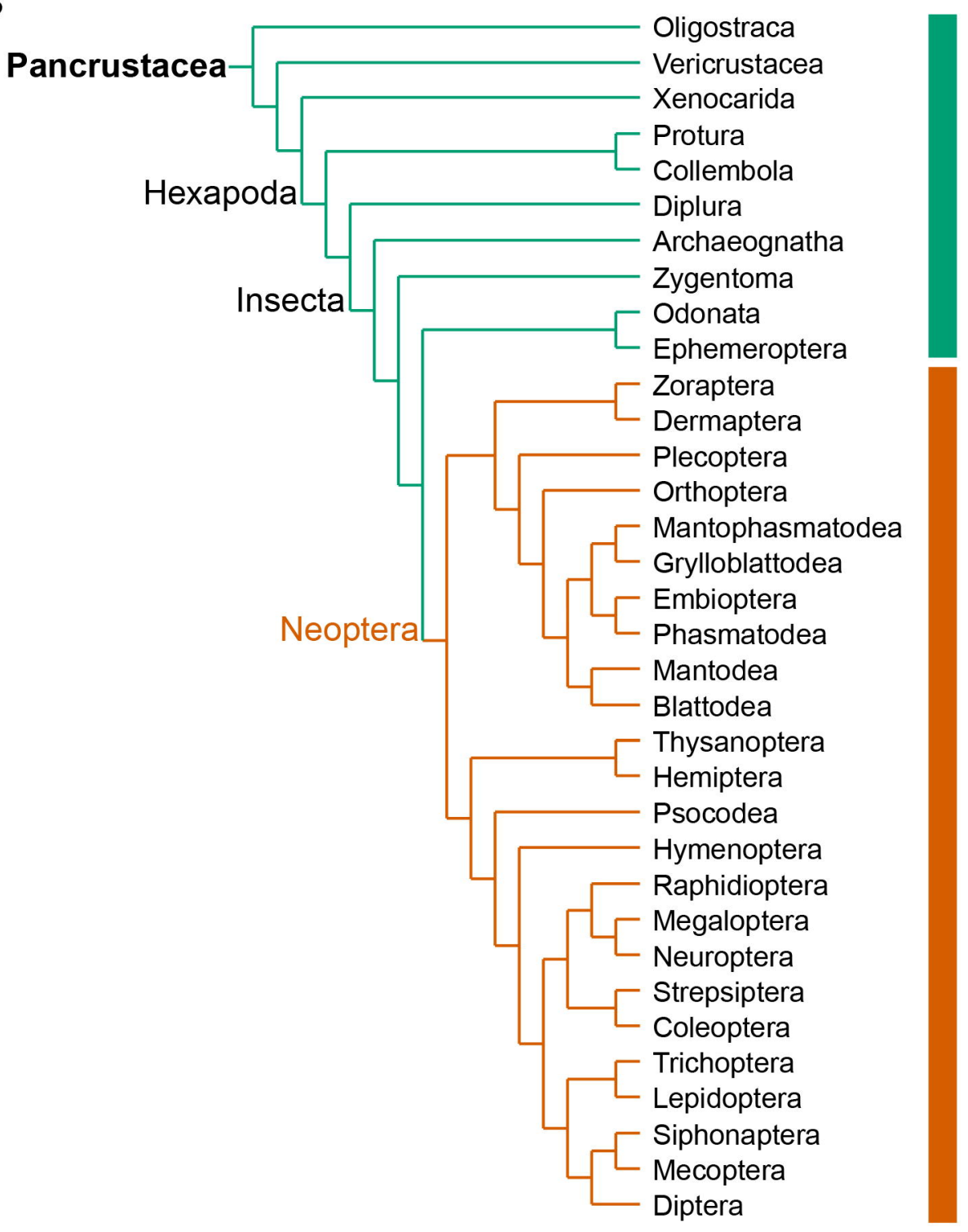

$\mathrm{Su}(\mathrm{H}) \mathrm{N}$-terminal Region Retains Ancestral Motifs for Direct Co-Repressor Recruitment

$\mathrm{Su}(\mathrm{H}) \mathrm{N}$-terminal Region Lacks Co-Repressor Recruitment Motifs 
A

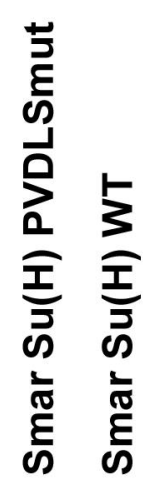

input

protein

GST-dCtBP

bound

12 lane

B

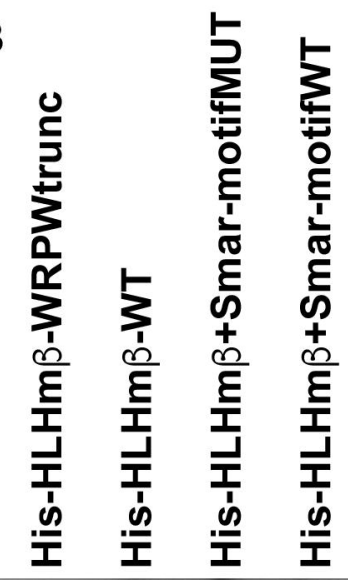

Input

Pulldown:

GST-Gro

GST-Gro protein

Pulldown:

GST

GST protein

$\begin{array}{lllll}1 & 2 & 3 & 4 & \text { lane }\end{array}$ 
A

Dmel Hairless

Smar S-CAP

Hsub S-CAP

Agir S-CAP

Ptep S-CAP

Hruf S-CAP

Ssca S-CAP

Vjac S-CAP

Iper S-CAPa

Mmar S-CAP

Lpol S-CAPa

B

Dmel Hairless

Smar S-CAP

Ptep S-CAP

Lpol S-CAP

Mmar S-CAP

Isca S-CAP

C
223 HGNNSWGGYGGRLQFFKDGKF ILELARSKDGDKSGWVSVTRKTFRPPSAA 272 $|+||+||+|||||$

77 RTGSSENDTNGKLSFYLDGRF ILELEHKPGGKRRNGGWIQTKGITWMPRP 126 ||| |||||||+|||

68 EENVGNSNLNGKLRFYLDGRFVLELRHTSDELTHAGKWIPSEEKYKGDNQ 117 $|+|||+|||||||| \mid$

248 SSSIVQQESSGRLRFFLDGRFVLELTHAGDNTRNTSGWVQSKGKIWTPSS 297 $|+|||||+|| \mid$

265 PQDVPATSTVGSLKFFLGGRLVLKLNAQQDGGSGNKCQWVOSNDLPKHSN 314 ||||$+||||||$

336 QESSGSISTVGSLKFYKDGQLVLKLNAQQEDTGQKCLWIESQDTPKLPRP 385 ||$+||+|||+|$

501 NEADSSKTNLGSINLYLHGELVLRLNAOQQDSGQKWVESNEIOSSFKDDA 550 ||$+|||+|+|+|$

288 GAGGGAAPGQGSLKFYLGGOLILKLNHOAHQERKSWVEAPDNPAOVTSPA 337 ||||$|+||||+|||$

294 EESPASVAPVGSIKFFLGGRLVLKLSAQEGGAWVEAQDTPRLGRPROPPP 343 || | ||||| |||||

275 SNNESTSFNLGSLSFFLGGQLVLKLNAQQENGPDNQNCQWVLSODTPKLP 324 || |++ | |||||

283 ATLDLETSPLGSLQFYFHGKLVLKLNAQQHANTNGHQCQWVPSVDTPKVP 332

GGTGGTCGTTTGCAGTTCTTTAAAG/ATGGCAAATTCATATTGGAACTGGCGCGGTCC $\begin{array}{lllllllllllllllllll}G & G & R & L & Q & F & F & K & D & G & K & F & I & L & E & L & A & R & S\end{array}$ AATGGCAAACTTAGTTTTTATTTGG/ACGGCCGATTCATCTTGGAATTGGAACACAAA

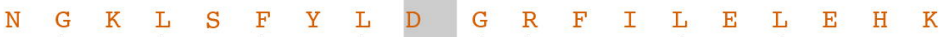
GTTGGAAGCTTGAAATTTTTTTTAG/GAGGTCGTTTAGTACTTAAATTAAATGCGCAA $\begin{array}{llllllllllllllllllll}V & G & S & L & K & F & F & L & G & G & R & L & V & L & K & L & N & A & Q\end{array}$ +||$|++|+|+||| \mid$ CTTGGAAGCCTTCAGTTCTATTTCC/ATGGAAAACTGGTTCTGAAACTTAATGCCCAA $\begin{array}{llllllllllllllllllll}L & G & S & L & Q & F & Y & F & H & G & K & \text { L } & \text { V } & \text { L } & K & \text { L } & N & \text { A } & \text { Q }\end{array}$ СTTGGAAGTTTAAGTTTTTTCCTTG/GAGGCCAGTTGGTACTGAAATTAAATGCCCAA СTTGGAAGTTTAAGTTTTTTCCTTG/GAGGCCAGTTGGTACTGAAATTAAATGCCCAA $\begin{array}{lllllllllllllllllll}I & G & S & L & S & F & F & L & G & G & Q & L & V & L & K & L & N & A & O \\ + & \mid & \mid & \mid & & \mid & \mid & \mid & \mid & \mid & & \mid & \mid & \mid & \mid & \mid & & \mid & \end{array}$ GTGGGCAGCСTCAAGTTCTTCСTCG/GCGGCCGCСTGGTGTTGAAGTTGAGCGCCCAG $\begin{array}{llllllllllllllllllll}V & G & S & L & K & F & F & L & G & G & R & L & V & L & K & L & S & A & Q\end{array}$

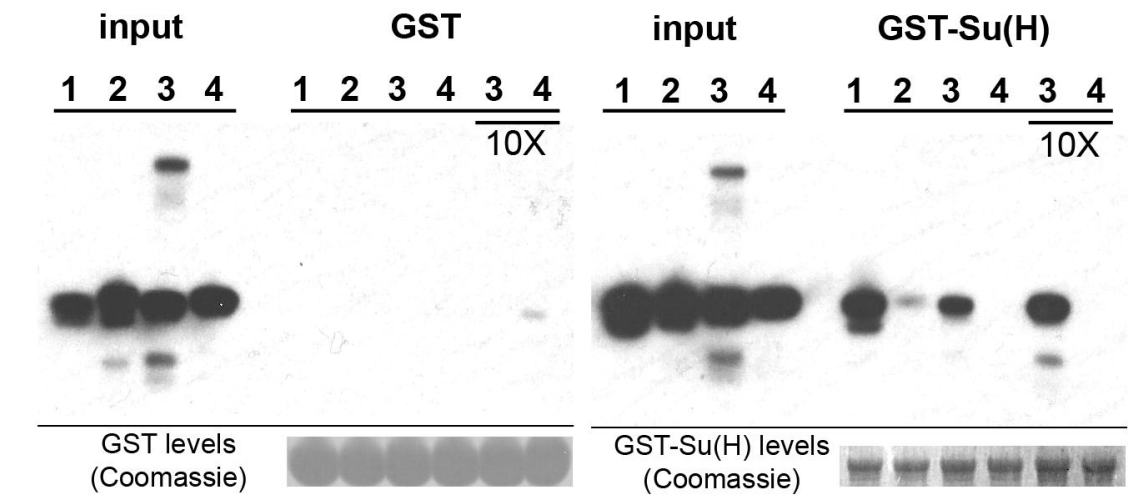

HIS-tagged constructs:

1) Dmel Hairless 192-389

2) Dmel Hairless 192-389 5Amut

3) Ptep S-CAP 233-432

4) Ptep S-CAP 233-432 5Amut 


\begin{tabular}{|lll|}
\hline $\mathbf{A}$ & $\mathbf{s}$ & PLDLR \\
\hline
\end{tabular}

Strigamia maritima S-CAP (Myriapoda; Geophilomorpha)

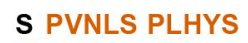

PVDIS PMDLR PVDYS

PVDFS

1289

Anopsobius giribeti S-CAP (Myriapoda; Lithobiomorpha)

\section{s}

PLDLS

798

Parasteatoda tepidariorum S-CAP (Arachnida; Araneae)

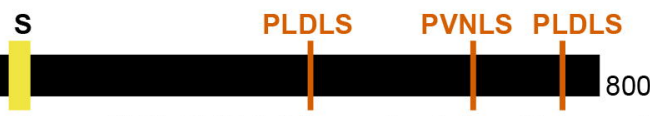

Mesobuthus martensii S-CAP (Arachnida; Scorpiones)

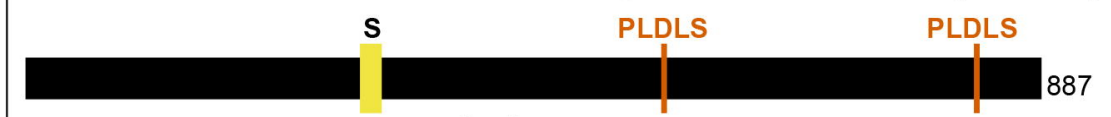

\section{Limulus polyphemus S-CAP (Merostomata; Xiphosura)}

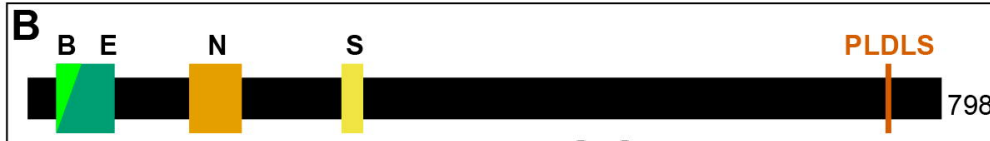

Parasteatoda tepidariorum S-CAP (Arachnida; Araneae)

Parasteatoda tepidariorum MTA (Arachnida; Araneae)

\section{C} B

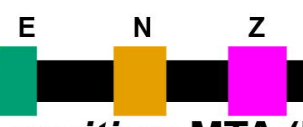

Strigamia maritima MTA (Myriapoda; Geophilomorpha)

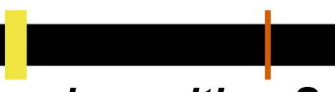

482

G/GC
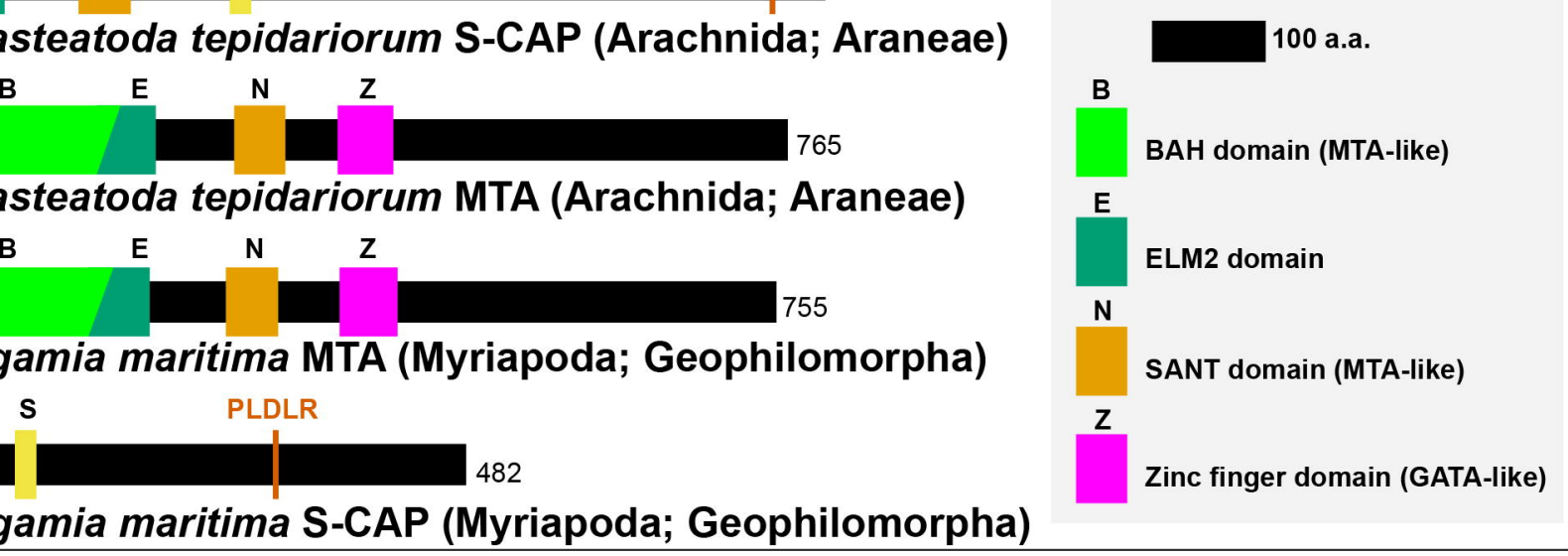

Ptep MTA ELM2

Ptep S-CAP ELM2

Ptep MTA SANT

Ptep S-CAP SANT

CRDEMEEWSASEANLFEEALEKYGKDF IDVRODF / LPWKSLKNVIEYYYMWKTTDRY

|| ||| || ||| || | ++ +| ||||++ + |||| |

SKVNTNTWSOSEAQLFAQALEACGKNFSAIKKEF / LPWKPVRS I IEYYYQIKNEKAE

G/GC

Lpol MTAa ELM2 ADKGE IRVGSRYQAEITPILKEGEEDGRRLEDLETIVYTPHHNLSDRQIDQFLI ICRSIGTFARALD +||||||$++||||||||||||++|||||+||++|+|||+|$ KNRNRIRVGRQYQATVPQLLKPGESDGRQLEDLETLKWKPNNDLSDQQLDQFFSVARAVSFFARAID G/GA

Lpol S-CAPa ELM2

Lpol MTAa SANT

CRDEMEEWSASEANLFEEALEKYGKDF IDIRODF / LPWKSLKNIVDYYYMWKTTDRH $+|+|||||||||||+|||||+||++| \mid$ GSNSSNDWTYGEAQLF ARALEACGKNFGAIKKDF / LPWKPVKS I IEYYYQGKEERPN 


$$
\text { (1) }
$$


A Dm CG15309

Hs YPEL1

Dm CG15309

HS YPEL1

Dm Hairless SBD

Smar S-CAP SBD

Agir S-CAP SBD

Ptep S-CAP SBD

Mmar S-CAP SBD

Lpol S-CAPa SBD
MVK-----TFQAYLPSTNRTYSCVHCRAHLASHDELISKSFQGSOGPAYLFNSVVNVACGQTEER

|| | MVKMTKSKTFQAYLPNCHRTYSCIHCRAHLANHDELISKSFQGSOGRAYLFNSVVNVGCGPAEER

VLLTGLHAVADIYCECCKTPLGWKYEHAYESSOKYKEGKF I IELAHMIKENGWD |||||||||||||| ||| ||||||||+||||||||||||||||||+|||+ VLLTGLHAVADIYCENCKTTLGWKYEHAFESSQKYKEGKF I IELAHMIKDNGWE

$$
|+|+||||+|| \mid
$$

GGRLQFFKDGKF ILELARS NGKLSFYLDGRF ILELEHK SGRLRFFLDGRFVLELTHA VGSLKFFLGGRLVLKLNAQ LGSLSFFLGGQLVLKLNAQ LGSLQFYFHGKLVLKLNAQ

Tribolium castaneum senseless (exon 2)

/ ATGAGGAGGCGCCCCTCAACCTGTCCCTCAAGGGCCGGTCGCGCAGCCAC . . .

$\begin{array}{lllllllllllllllll}\mathrm{E} & \mathrm{E} & \mathrm{A} & \mathbf{P} & \mathbf{L} & \mathbf{N} & \mathbf{L} & \mathbf{S} & \mathrm{L} & \mathrm{K} & \mathrm{G} & \mathrm{R} & \mathrm{S} & \mathrm{R} & \mathrm{S} & \mathrm{H} & \ldots\end{array}$

/ ACGTGCCGCTGAACCTGTCTAAGCATTGA

$\begin{array}{lllllllllll} & \mathbf{P} & \mathbf{L} & \mathbf{N} & \mathbf{L} & \mathbf{S} & \mathrm{K} & \mathrm{H} & \text { * }\end{array}$

Bactrocera dorsalis Hairless (last exon) 


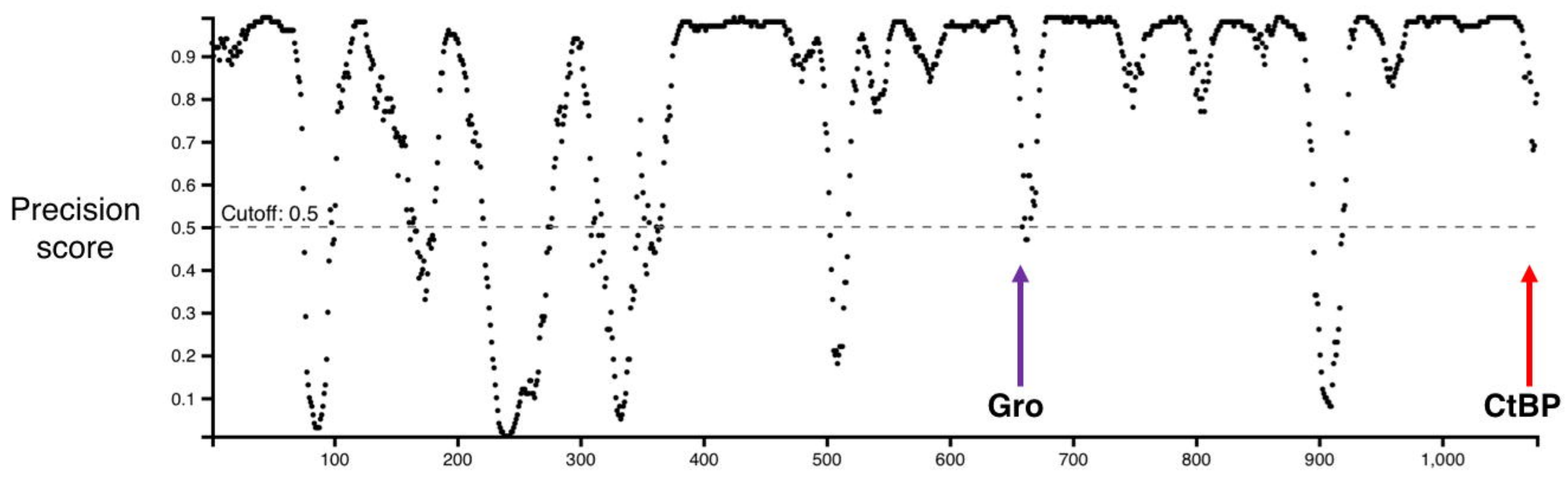

Amino acid position 
Hruf S-CAP ELM2

Lpol S-CAPa ELM2

Otur S-CAP ELM2

Tser S-CAP ELM2

Lhes S-CAP ELM2
21 PNRNRIRIGROYQATVPPLLKPGESDGRKLEELETLRWKPDNELSDQOLDOYLSVAK-AVSLFA 83 ||||||$+||||||||||||||||||||+|||+||||+||||||||++|||+|||+| \mid$ 20 KNRNRIRVGRQYQATVPQLLKPGESDGRQLEDLETLKWKPNNDLSDQQLDQFFSVAR-AVSFFA 82 ||||||||||||||||||||||||||||||$+|+| \quad||||+|++|+|+|||+||$ 19 NNRNRIRVGRQYQATVPPLLKPGESDGRRLEDLETLRWRPES-LSDQSIDEYLSMAK-AVSLFA 80 ||||||||||||||||||||||+||| ||||||+|+|+ |||| || ||||| |||||| 25 RNRNRIRVGRQYQATVPPLLKPGETDGRCCEDLETLKWKPDNDLSDQQIDQYLSMASRAVSLFA 88 |||||||||||||+|||||||| ||| |||||||||||++ ||||++ |+|||+ +|| 21 QNRNRIRVGRQYQATIPPLLKPGEKDGRKCEDLETLKWKPEQ-LSDQKLEEYMSMAK-GISLFS 82

133 SASVGDHHIQSALKGLSDFVTSHHPGHHDAGCRVSDP 169 l $\quad||+||+||+++||||||||||+\mid$

91 SDKESDKCIQTALRGLTEYVTSHHPCHHDANCQLSQG 127 $|+|||+||||+||+++||||||||||+$

Additional

89 SEEASDGCLQTALKGLSDFVTSHHGCHHDAGCQVGPS 125 $+\quad|||||+|||||||||||||||||$

97 TGNGPDKTLQTALRGLSDFVTSHHPCHHDAGCQVPSP 133 Conserved Region

Tser S-CAP

Lhes S-CAP

90 TSEKSDNSLQSAIKGLTEFVASHHPYHHDDGCRQVPK 126

Hruf S-CAP SANT

Lpol S-CAPa SANT

Otur S-CAP SANT

Tser S-CAP SANT

Lhes S-CAP SANT
185 SGLITGEWTPNEMKLFTRALDVCGKNFGAIKKEFLPWKSVKSIIEHYYLGIDKLLS 240 $++1|\quad|||||+|||||||||+|||||||||||||+$

135 GSNSSNDWTYGEAQLFARALEACGKNFGAIKKDFLPWKPVKSIIEYYYQGKEERPN 190 $|\quad| 1|+1| 1|1|+|1| 1|1| 1|1| 1|1| 1|1+1| 1|1| 1 \mid+$

123 GPSLPSDWTPNEASLFARALDECGKNFSAIKKDFLPWKPVKSLIEYYYQGKLEKQD 178 I+

142 KHSIKNGWTPTEAHLFARALEACGKNFGAIKKEFLPWKPVRSIIEFYYNGKEEKYD 197 ||$+|||||||||||||||||||||||||||+||+|||+$ 135 PKISTNVWSPFEAQLFAQALESCGKNFCAIKKEFLPWKPVRSIIEYYYQIKNEKNE 190
B

Smar S-CAP

Agir S-CAP

Smar S-CAP

Agir S-CAP

Smar S-CAP

Agir S-CAP

\section{Alignment of Myriapod mS-CAP Conserved Regions}

262 PDNASLPLPEWYLDPSKSOIPVNEMIGNPRPYLPAAPTH 300

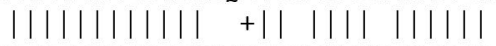

534 ASSSNLPLPEWYLDPSKAEVPVSEMIGYPRPYLPPSTDS 572

361 PSAVQPWPCVSCPVVAYAPTVVNSYYYCCCFLPGCRSNCLCKTEGKQLTS 410

+||||||||$|+|||||||||||||+|1|++$

1009 SIGLAPWPYPPCPVVAYGPALVNSYYYCCCFLPGCRFHYMYNTEGRPVIA 1058 